\title{
A Single Point Mutation Converts a Proton-pumping Rhodopsin into a Turn-on Fluorescent Sensor for Chloride
}

Jasmine N. Tutol ${ }^{\dagger}$, Jessica Lee ${ }^{\dagger, \ddagger}$, Hsichuan Chi ${ }^{\dagger, \ddagger}$, Farah N. Faizuddin ${ }^{\dagger, \neq}$, Sameera S. Abeyrathna $^{\dagger}$, Qin Zhou ${ }^{\ddagger}$, Faruck Morcos ${ }^{\ddagger}, \S$, Gabriele Meloni ${ }^{\dagger}$, and Sheel C. Dodani ${ }^{\dagger}$

Departments of ${ }^{\dagger}$ Chemistry and Biochemistry, ${ }^{\ddagger}$ Biological Sciences, and ${ }^{\text {\$Bioengineering, }}$ The University of Texas at Dallas, Richardson, TX 75080

*sheel.dodani@utdallas.edu

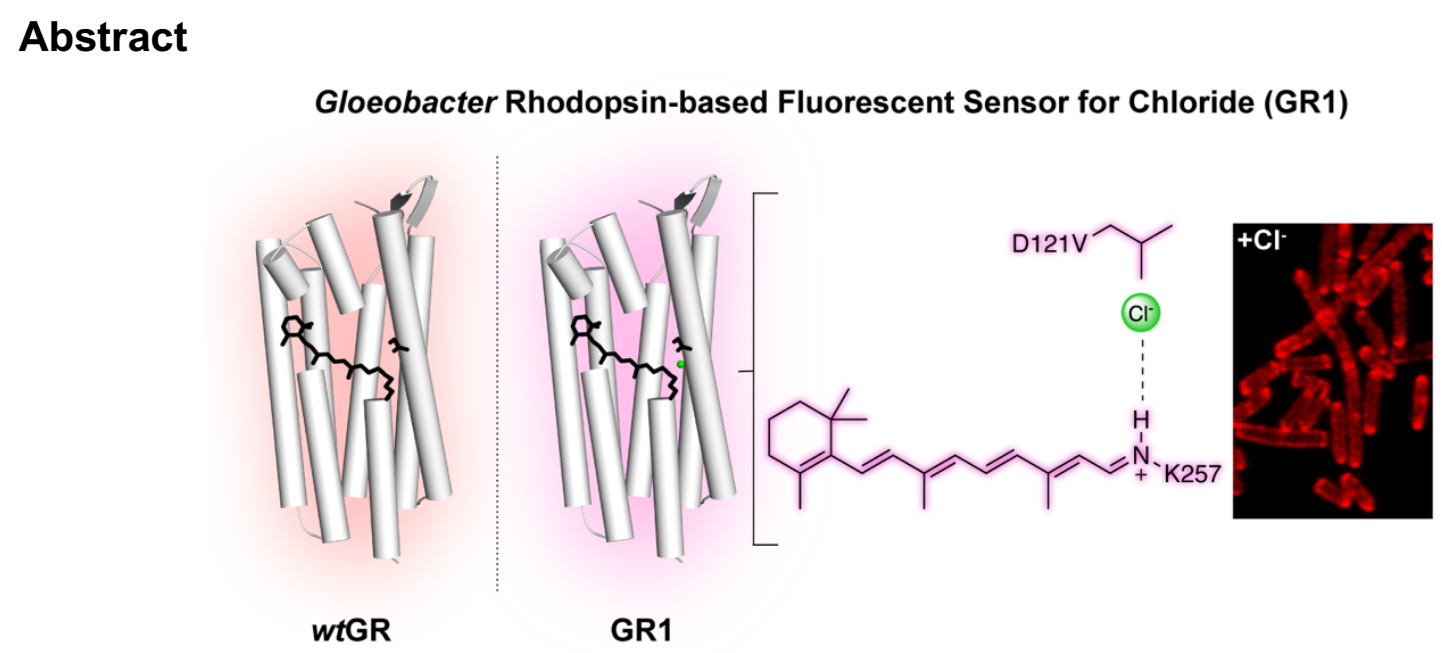

The visualization of chloride in living cells with fluorescent sensors is linked to our ability to design hosts that can overcome the energetic penalty of desolvation to bind chloride in water. Fluorescent proteins can be used as biological supramolecular hosts to address this fundamental challenge. Here, we showcase the power of protein engineering to convert the fluorescent proton-pumping rhodopsin GR from Gloeobacter violaceus into GR1, a turn-on fluorescent sensor for chloride in detergent micelles and in live Escherichia coli. This non-natural function was unlocked by mutating D121, which serves as the counterion to the protonated retinylidene Schiff base chromophore. Substitution from aspartate to valine at this position (D121V) creates a binding site for chloride. The addition of chloride tunes the $\mathrm{p} K_{\mathrm{a}}$ of the chromophore towards the protonated, fluorescent state to generate a $\mathrm{pH}$-dependent response. Moreover, ion pumping assays combined with bulk fluorescence and single cell fluorescence microscopy experiments with $E$. coli, expressing a GR1 fusion with cyan fluorescent protein, show that GR1 does not pump ions nor sense membrane potential but instead provides a reversible, ratiometric readout of chloride. This discovery sets the stage to use natural and laboratory-guided evolution to build a family of rhodopsin fluorescent chloride sensors for cellular applications and learn how proteins can evolve and adapt to bind anions in water. 


\section{Introduction}

Chloride is an essential inorganic ion for life ${ }^{[1,2]}$ Beyond its role as an electrolyte, chloride mobilization across cellular membranes is known to be involved in a wide range of homeostatic processes including, but not limited to, $\mathrm{pH}$ regulation, fluid excretion, and electrical activity. ${ }^{[2-4]}$ The growing importance of chloride in normal physiology and disease is further evident by recent discoveries of new transporters and biological roles, which have been accelerated through the application of fluorescent sensors for chloride. ${ }^{[5-9]}$ The fluorescence imaging of chloride in living cells is linked to our ability to build hosts that can recognize chloride in water, a fundamental challenge in the field of supramolecular chemistry. ${ }^{[10-12]}$ Advances along these lines could contribute to our general understanding of aqueous anion recognition and to the design of new fluorescent sensors for chloride.

A key limitation for the recognition of chloride in water is the inherent energetic penalty for desolvation. ${ }^{[10,12-15]}$ To overcome this, successful examples of fluorescent molecular and polymer hosts integrate Nature's design principles and combine cooperative, noncovalent interactions, including hydrogen bonding, ion-pairing, and van der Waals with the hydrophobic effect. ${ }^{[4,11,16-20]}$ However, synthetic hosts that allow for the fluorescence imaging of chloride in living cells remain rare. Quinolinium and acridinium-based fluorophores bear a positively charged pyridinium cation that directly interacts with chloride, resulting in collisional fluorescence quenching. ${ }^{[11,18,21,22]}$ These molecular fluorescent sensors are $\mathrm{pH}$-independent, and additional bioconjugation strategies have enabled improved cellular uptake, organelle targeting, and ratiometric fluorescent outputs. ${ }^{[4,23-28]}$

As a complementary approach, we use and evolve Nature to build protein-based hosts for chloride. Even though there are only twenty proteinogenic amino acids, protein sequence space is vast and can be further enriched through protein engineering methods. ${ }^{[29]}$ By selecting for a desired function or property, laboratory-guided evolution allows for this sequence space to be quickly sampled and filtered. ${ }^{[29]}$ For our goal, this approach affords a diverse pool of hosts that can further evolved and applied for the fluorescence imaging of chloride in living cells. Along these lines, the green fluorescent protein family (GFP, PF01353) has been widely explored and engineered to build fluorescent sensors for chloride. ${ }^{[4,30,31]}$ Indeed, pioneering work from Wachter and Remington established that variants of the green fluorescent protein (avGFP) from the jellyfish Aequorea victoria are sensitive to chloride. ${ }^{[32-34]}$ Of these, the yellow fluorescent protein avYFP-H148Q is well characterized, and the chloride binding pocket is lined with hydrophobic residues and four polar amino acids, including two glutamines, arginine, and tyrosine, that can hydrogen bond with the chloride ion. ${ }^{[34]}$ The latter tyrosine residue connects the binding of chloride through a $\pi-\pi$ interaction with the 4-(phydroxybenzylidene)imidazolidin-5-one chromophore. ${ }^{[34]}$ Because of this close proximity, chloride binding increases the $\mathrm{p} K_{\mathrm{a}}$ of the chromophore and shifts the equilibrium from the fluorescent phenolate state towards the non-fluorescent phenol state, generating a turnoff fluorescence response. ${ }^{[34,35]}$ The $E^{2}$ GFP variant of avGFP is also sensitive to chloride but operates via static fluorescence quenching with no change in the chromophore 
equilibrium. ${ }^{[36]}$ This sensing mechanism could be attributed to a different chloride binding pocket; the chloride ion forms an electrostatic interaction with the imidazoline ring of the chromophore and three hydrogen bonds: one with a tyrosine residue and two with the peptide backbone connecting the chromophore to valine and glutamine residues. ${ }^{[36]}$ Both avYFP-H148Q and $E^{2}$ GFP, and variants thereof, have been applied for the fluorescence imaging of chloride. ${ }^{[31,35,37-41]}$ Furthermore, fusion with other fluorescent proteins have enabled ratiometric fluorescent outputs that account for variability in protein expression or $\mathrm{pH}$ dependence in living cells. ${ }^{[42-47]}$

Relative to these literature precedents, we have identified low sequence identity homologues that are also sensitive to chloride. ${ }^{[48,49]}$ The chloride binding pocket in the naturally occurring yellow fluorescent protein from the jellyfish Phialidium $s p$. (phiYFP) is identical to that of avYFP-H148Q. ${ }^{[34,50]}$ Similarly, chloride binding increases the $p K_{a}$ of the chromophore but also generates an excitation ratiometric, turn-on fluorescence response, likely through an excited state proton transfer process. ${ }^{[48]}$ In addition, through a structureguided search, we identified that the yellow fluorescent protein lanYFP from the cephalochordate Branchiostoma lanceolatum and its engineered monomer mNeonGreen also bind chloride. ${ }^{[51]}$ In mNeonGreen, chloride forms five hydrogen bonds with histidine, arginine, serine, threonine, and tyrosine residues near the chromophore. ${ }^{\left[{ }^{[1]}\right.}$ Based on this, we recently reported that chloride binding decreases the $\mathrm{p} K_{\mathrm{a}}$ of the chromophore and shifts the equilibrium from the non-fluorescent phenol state to the highly fluorescent phenolate state, generating a turn-on fluorescence response. ${ }^{[49]}$ Furthermore, we attributed this unique sensing mechanism to a non-coordinating arginine residue, instead of a tyrosine residue, above the chromophore. Together, these homologues highlight how differences in the amino acid residues, within and outside of the chloride binding pocket and even in the chromophore, can influence sensor properties. This is a key advantage of sampling and enriching the vast protein sequence space to build hosts for chloride.

Building off of the green fluorescent protein family, we envisioned that microbial rhodopsins (Bac_rhodopsin, PF01036) could also serve as scaffolds to engineer fluorescent sensors for chloride. Microbial rhodopsins are light-activated, transmembrane ion pumps with seven $\alpha$-helices and a covalently bound retinylidene Schiff base chromophore (SBC) - generated from the condensation of all-trans-retinal and a lysine residue (Figure $1 \mathrm{~A}){ }^{[52-56]}$ The $\mathrm{SBC}$ and its protonation state are stabilized by a key counterion position, which plays a role in the ion pumping pathway and selectivity. ${ }^{[57]}$ In chloride-pumping rhodopsins (CPRs), this counterion position corresponds to a threonine or asparagine, such that the chloride ion serves as the counterion to the protonated SB. ${ }^{[52,54,57-63]}$ This is observed in the X-ray crystal structures of representative CPRs from Halobacterium salinarum (HR) and Nonlabens marinus $\mathrm{S} 1-08^{\top}(\mathrm{CIR})$ (Figures 1B1C). ${ }^{[58,61,62]}$ The chloride binding pocket also consists of polar amino acids, including serine and threonine, and highly ordered water molecules that can form hydrogen bonding interactions with the chloride ion. ${ }^{[61,62]}$ However, the homologous counterion position in proton-pumping rhodopsins (PPRs) corresponds to a negatively charged aspartate, which accepts the proton from the protonated SBC (Figure 1D).[54,60,64] Interestingly, the well-studied PPR bacteriorhodopsin (BR) from Halobacterium salinarum can be converted into a CPR by substituting the aspartate counterion position (D85) with 
serine, threonine, or asparagine. ${ }^{[65]}$ Absorption spectroscopy indicates that these variants bind chloride and other anions including bromide, iodide, and nitrate, but with varying pumping activities. ${ }^{[65-68]}$ Of the three variants, BR D85S has been crystallized with bromide (Figure 1E). ${ }^{[69]}$ Similar to CPRs, the serine residue at the counterion position directly interacts with the bromide ion, which forms a hydrogen bond with the protonated SBC. ${ }^{699}$ The residues R82, mediated by a highly ordered water molecule, and D212 form two hydrogen bonding interactions with bromide, thus adapting to accommodate this nonnatural function. ${ }^{[69]}$ Outside of these contexts, when illuminated with near-infrared light, PPRs can also access fluorescent states in the photocycle. ${ }^{[70-73]}$ Because of this property, engineered PPRs have been repurposed as fluorescent proton sensors to provide a readout of the membrane potential in living cells. ${ }^{[71,72,74-76]}$ On a molecular level, the protonation state of the SBC controls the on and off fluorescent states, which can be influenced by the counterion position. ${ }^{[71,72]}$

A

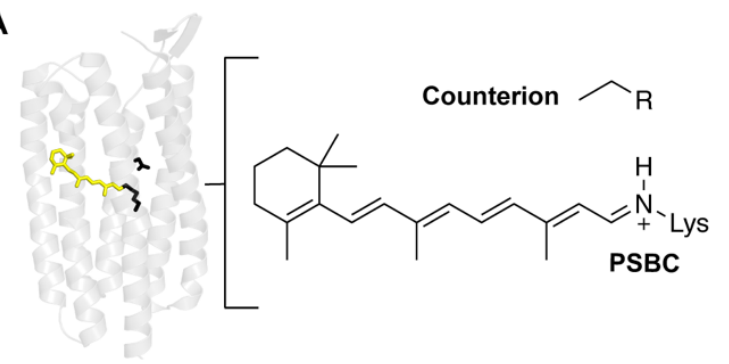

B

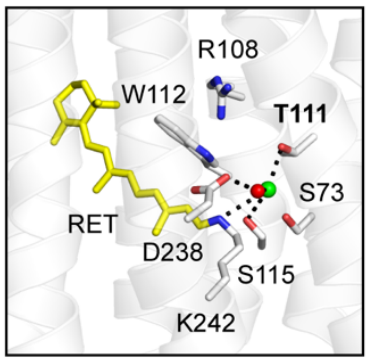

C

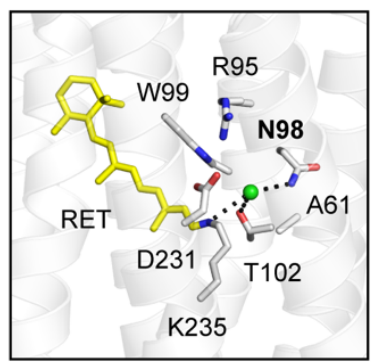

D

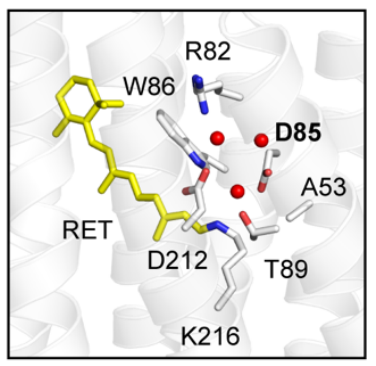

E

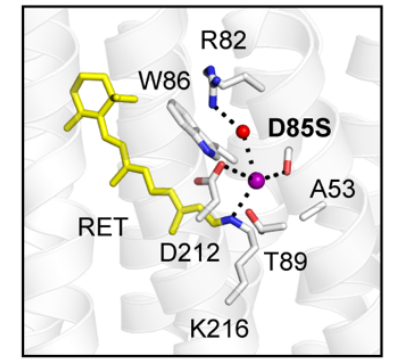

$\mathbf{F}$

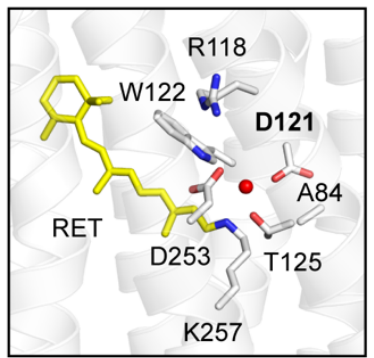

Figure 1. (A) Microbial rhodopsins are light-activated, transmembrane ion pumps with a covalently bound retinylidene Schiff base chromophore (SBC), formed from all-trans-retinal (yellow sticks) and a conserved lysine residue (Lys, black sticks). The counterion position (black sticks) stabilizes the protonated SBC (PSBC) and controls ion selectivity (PDB ID: 6NWD). Comparison of $(B)$ the chloride-pumping rhodopsin (CPR) from Halobacterium salinarum (HR) with chloride (PDB ID: 5AHY), (C) the CPR from Nonlabens marinus S1-08 ${ }^{\top}(\mathrm{CIR})$ with chloride (PDB ID: 5G28), (D) the proton-pumping rhodopsin (PPR) from Halobacterium salinarum (BR, PDB ID: 1KGB), (E) the engineered PPR BR D85S with bromide (PDB ID: 1MGY), and (F) the fluorescent PPR from Gloeobacter violaceus (wtGR, PDB ID: 6NWD) selected for this study. For each structure, the residues corresponding to the anion binding pocket in the CPRs and BR D85S are shown as light gray sticks with the oxygen (red) and nitrogen (blue) atoms. Hydrogen bonds are shown as black dashed lines. Each residue is labeled with the position number and the single letter amino acid code. The retinal (RET) is shown as sticks in yellow covalently bound to conserved lysine residue, generating the SBC. The counterion position to the SBC is labeled in bold. The water molecules, chloride ions, and bromide ion are shown as spheres in red, green, and purple, respectively. 
Motivated by these studies, we hypothesized that chloride could replace the aspartate as the counterion in a fluorescent PPR, form an electrostatic interaction with the protonated SBC, and tune the optical properties to generate a fluorescent sensor for chloride. To test this, we selected the fluorescent PPR from the cyanobacterium Gloeobacter violaceus (GR) because it has been spectroscopically and structurally characterized, can readily be expressed in Escherichia coli, and remains fluorescent even after the introduction of multiple mutations (Figure 1F). ${ }^{[77-89]}$ We have developed a workflow to rapidly evolve, screen, and discover chloride-sensitive variants of GR. Based on this screen, we highlight how a single point mutation at the SB counterion position from aspartate to valine, a nonnatural substitution, converts wild-type (wt) GR into GR1, a pH-dependent, turn-on fluorescent sensor for chloride. In vitro data indicate that chloride binding to GR1, but not $w t G R$, increases the $p K_{a}$ of the $\mathrm{SBC}$, shifting the equilibrium towards the protonated, fluorescent state, generating the turn-on response. lon pumping assays combined with bulk fluorescence measurements and single cell fluorescence imaging of live $E$. coli demonstrate that a GR1 does not pump ions nor sense membrane potential but instead is a reversible sensor for chloride.

\section{Results and Discussion}

\section{Fluorescence library screening and identification of GR sensors for chloride}

The fluorescence of wild-type (wt) GR was evaluated in live $E$. coli at $\mathrm{pH} 5,6$, and 7 in the absence and presence of $400 \mathrm{mM}$ sodium chloride. To account for any variability in protein expression, wtGR was fused to a chloride-insensitive cyan fluorescent protein (CFP) to generate the wtGR-CFP construct resulting in a ratiometric output for normalization (Figures S1-S3). ${ }^{[88]}$ Upon excitation at $530 \mathrm{~nm}$, the rhodopsin-based emission of wtGR-CFP is centered at $710 \mathrm{~nm}$ and does not change in the presence of chloride (Figures 2, S3). Next, site-saturation mutagenesis (SSM) was carried out at position 121 to sample all possible amino acid substitutions that could give rise to a chloride-sensitive variant. To our surprise, mutation from aspartate to valine (GR1-CFP) results in a ca. 2.2-fold turn-on fluorescence response with $400 \mathrm{mM}$ sodium chloride at pH 5 (Figures 2, S4-S5). In addition, substitution with leucine (ca. 1.2-fold), threonine (ca. 1.3-fold), asparagine (ca. 1.3-fold), or isoleucine (ca. 1.5-fold) result in a turn-on fluorescence response, albeit to a lesser extent (Figures S4, S6-S9). No chloridesensitive variants were identified in the library screen at $\mathrm{pH} 6$ or $\mathrm{pH} 7$. However, upon rescreening, GR1-CFP shows a ca. 1.2-fold turn-on fluorescence response at $\mathrm{pH} 6$ (Figure 2). Given these results, the CFP tag was removed from the wtGR and GR1 constructs, and comparable results were observed in live E. coli (Figure S10). Interestingly, asparagine and threonine are enriched at this counterion position in a subset of CPRs, whereas, the hydrophobic substitutions, such as leucine, isoleucine, and valine, have yet to be identified at this position in the rhodopsin family (sequence identity $>23 \%$, Figure S4C). 


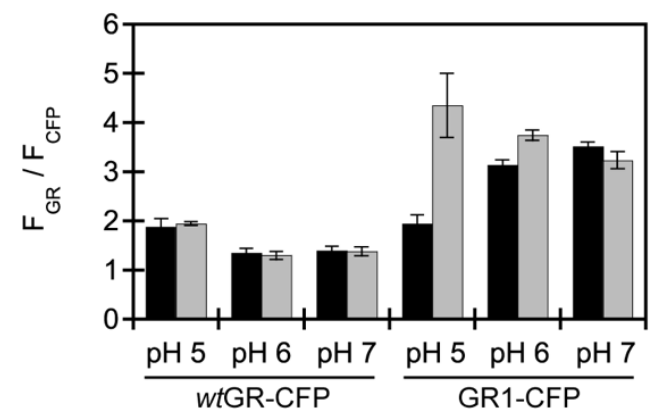

Figure 2. Site-saturation mutagenesis at the $D 121$ counterion position converts wtGR-CFP into the chloride-sensitive variant GR1-CFP. Bars represent the integrated emission response of the rhodopsin $\left(F_{G R}\right)$ normalized by the integrated emission of CFP ( $\left.F_{C F P}\right)$ in the absence (black bars) and presence of $400 \mathrm{mM}$ sodium chloride (gray bars). Spectra were acquired with live Escherichia coli expressing wtGR-CFP or GR1-CFP in $50 \mathrm{mM}$ sodium acetate buffer at $\mathrm{pH} 5,50 \mathrm{mM}$ sodium phosphate buffer at $\mathrm{pH} 6$, and $50 \mathrm{mM}$ sodium phosphate buffer at $\mathrm{pH} 7$. Excitation for the rhodopsin was provided at $530 \mathrm{~nm}$ for the rhodopsin, and the emission was collected and integrated from $600-800 \mathrm{~nm}\left(\mathrm{~F}_{\mathrm{GR}}\right)$. Excitation for CFP was provided at $390 \mathrm{~nm}$, and the emission was collected and integrated from $425-560 \mathrm{~nm}$. The average of three biological replicates with standard error of the mean is reported.

\section{Spectroscopic characterization of purified wtGR and GR1}

Next, the in vitro properties of purified wtGR and GR1 in detergent micelles were compared in acetate buffer at $\mathrm{pH} 5$, supplemented with sodium gluconate for protein stability. ${ }^{[67,90,91]}$ Consistent with previously reported absorbance spectra, wtGR has one absorption maximum at $550 \mathrm{~nm}$ that corresponds to the covalently bound SBC (Figure S13). ${ }^{[78,79,84,85,87,89]}$ Upon excitation at $530 \mathrm{~nm}$, wtGR has a broad emission band with a maximum centered at $630 \mathrm{~nm}$ and a shoulder at $670 \mathrm{~nm}\left(\Phi_{\text {apo }}=2.0 \times 10^{-3}\right.$, Figures 3A, S14). ${ }^{[82]}$ The $w t G R$ absorption and emission maxima do not shift upon the addition of sodium chloride (Figure S13). Instead, the emission intensity fluctuates by $\sim 8 \%$ with no clear indication of binding $\left(\Phi_{\mathrm{Cl}}=2.4 \times 10^{-3}\right.$, Figures $\left.3 \mathrm{~A}, \mathrm{~S} 14\right)$. As expected, the absorption maximum of GR1 is red-shifted to $565 \mathrm{~nm}$ and does not change upon the addition of sodium chloride (Figure S15). ${ }^{[8]}$ However, with excitation at $530 \mathrm{~nm}, \mathrm{GR} 1$ displays a ca. 1.3-fold turn-on fluorescence response that saturates with $400 \mathrm{mM}$ sodium chloride at $655 \mathrm{~nm}\left(\Phi_{\text {apo }}=3.0 \times 10^{-3}, \Phi_{\mathrm{Cl}}=3.9 \times 10^{-3}\right)$ with no shift in the emission maximum, suggesting an excited state process (Figures 3B, S14-S15). This titration data can be fitted to a single site binding model for chloride resulting in an apparent dissociation constant $\left(K_{d}\right)$ of $80 \pm 1 \mathrm{mM}$ (Figure S15). 


\section{A}

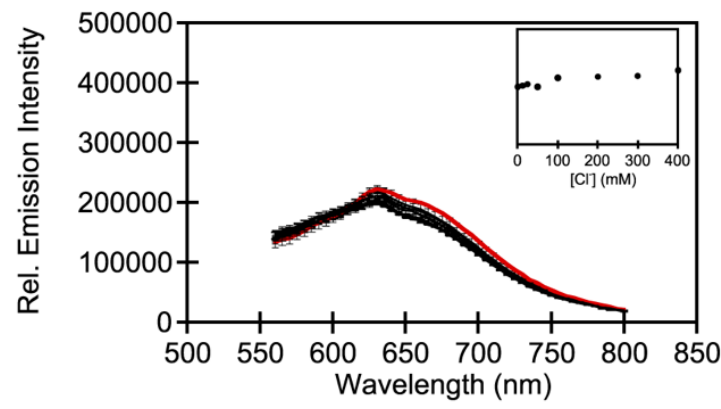

B

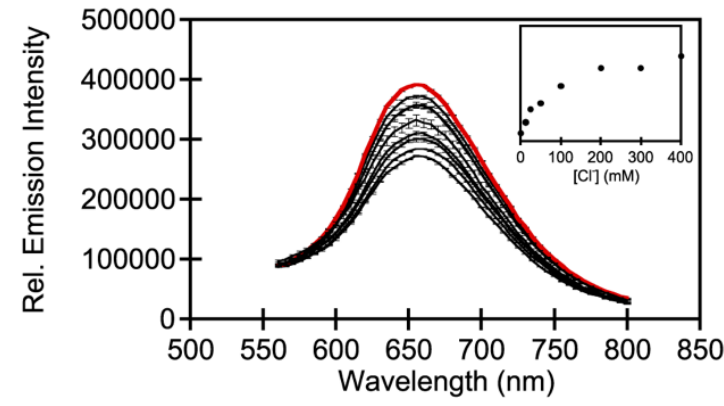

C

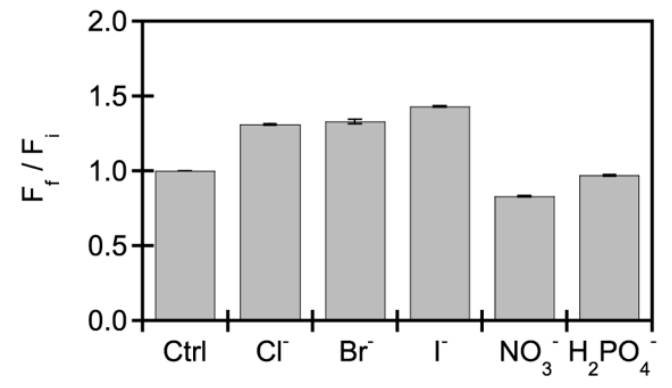

Figure 3. Characterization of purified wtGR and GR1 in detergent micelles shows that GR1 has a chloride binding site and is also sensitive to bromide, iodide, and nitrate. Fluorescence spectra of $\sim 3 \mu \mathrm{M}(\mathrm{A})$ wtGR and (B) GR1 in the presence of 0 (bold), 12.5, 25, 50, 100, 200, 300, and 400 (red) $\mathrm{mM}$ sodium chloride. Insets: Integrated emission response (y-axis) to sodium chloride. (C) Integrated emission response of $\sim 3 \mu \mathrm{M}$ GR1 to $0 \mathrm{mM}\left(\mathrm{F}_{\mathrm{i}}, \mathrm{Ctrl}\right)$ or $400 \mathrm{mM}\left(\mathrm{F}_{\mathrm{f}}\right)$ sodium chloride, bromide, iodide, nitrate, or dihydrogen phosphate. All spectra were acquired in $50 \mathrm{mM}$ sodium acetate buffer containing $600 \mathrm{mM}$ sodium gluconate at $\mathrm{pH} 5$. Excitation for the rhodopsin was provided at $530 \mathrm{~nm}$, and the emission was collected and integrated from 560-800 nm. The average of three technical replicates with standard error of the mean is reported.

Moreover, a turn-on fluorescence response is also observed with $400 \mathrm{mM}$ of sodium bromide (ca. 1.3-fold) and iodide (ca. 1.4-fold), but quenching is observed with sodium nitrate $(\sim 17 \%)$ and no change is observed with sodium hydrogen phosphate (Figure $3 \mathrm{C}$, S16). As described above, these anion preferences are also found in naturally occurring CPRs and engineered variants of the PPR BR, which suggests that the anion binding site in GR1 could be adjacent to the SBC. To determine how the binding of chloride generates the turn-on fluorescence response, we next measured the $\mathrm{p} K_{\mathrm{a}}$ of the $\mathrm{SBC}$ with fluorescence spectroscopy. The $\mathrm{p} K_{\mathrm{a}}$ for apo $w t \mathrm{GR}$ is $5.0 \pm 0.2$ and, as expected, does not significantly change upon the addition of $400 \mathrm{mM}$ sodium chloride $\left(\mathrm{p} K_{\mathrm{a}}=4.7 \pm 0.2\right.$, 
Figure S17). These pKa values are consistent with that previously reported for wtGR in the presence of $300 \mathrm{mM}$ sodium chloride using absorption spectroscopy. ${ }^{[85]}$ However, the $\mathrm{p} K \mathrm{a}$ for GR1 increases from $4.1 \pm 0.1$ to $5.1 \pm 0.3$ with $400 \mathrm{mM}$ sodium chloride (Figure $\mathrm{S} 18)$. This clearly indicates that the binding of chloride shifts the equilibrium towards the protonated, fluorescent SBC resulting in the observed turn-on fluorescence response. Even though in vitro purification of GR1 using detergent micelles is artificial and does not recapitulate the response observed in the library screening, our data demonstrates that mutation of the SBC counterion residue creates a chloride binding site, generating a turnon fluorescent sensor. We speculate that, like BR D85S, GR1 adapts to this new function. While the hydrophobic valine side chain cannot hydrogen bond with the chloride ion, it could interact through van der Waals forces. It is also likely that chloride interacts with the protonated SBC along with nearby hydrogen-bond donating residues or water molecules (Figures 1E-1F). These additional interactions combined with the desolvation of the chloride ion could contribute favorably to the overall driving force for chloride binding. Moreover, the gain from the desolvation of GR1 would likely be minimal since it is a hydrophobic, transmembrane protein. ${ }^{[13-15,92]}$

\section{Application and validation of GR1-CFP in live E. coli}

With in vitro characterization in hand, we turned our attention to validating GR1-CFP as a ratiometric fluorescent sensor for chloride in living cells using bulk and single cell fluorescence measurements. For this proof-of-concept, E. coli cells were selected due to their tolerance to $\mathrm{pH} 5$ buffer ${ }^{\left[{ }^{93]}\right.}$ Consistent with the library screening, cells expressing wtGR-CFP show a measurable level of fluorescence that does not change with increasing concentrations of sodium chloride (Figures 4A, S19). In contrast, the fluorescence of cells expressing GR1-CFP increases, in a dose-dependent manner, by ca. 2.5-fold with 400 $\mathrm{mM}$ sodium chloride with no interference from sodium acetate (Figures 4B, S20-S21). 
A

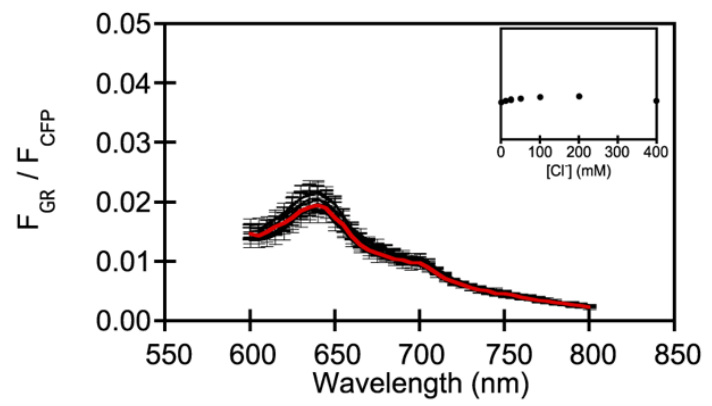

B

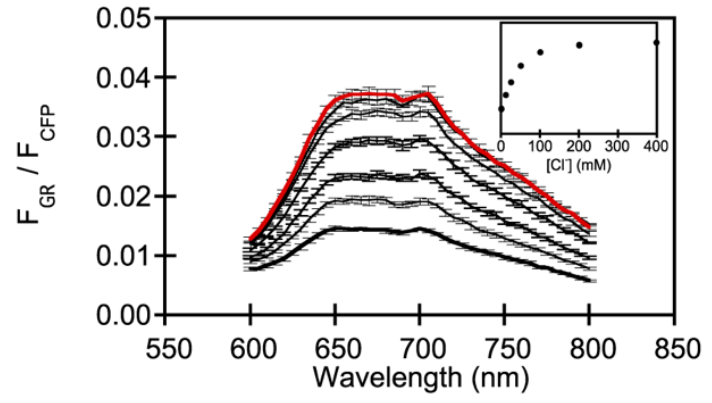

C

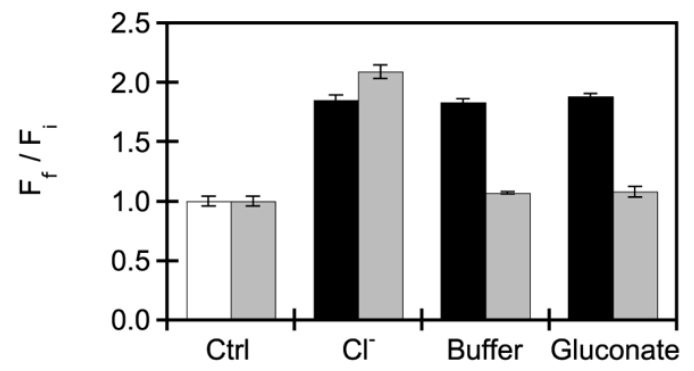

Figure 4. Bulk fluorescence measurements show that GR1-CFP is a ratiometric, turn-on fluorescent sensor that dynamically responds to changes in sodium chloride concentrations in live E. coli cells. Normalized fluorescence spectra of (A) wtGR-CFP and (B) GR1-CFP in the presence of 0 (bold), 12.5 25, 50, 100, 200, and 400 (red) mM sodium chloride. Inset: Integrated emission response of the rhodopsin $\left(F_{G R}\right)$ over the integrated emission of CFP ( $\left.F_{C F P}\right)$ (y-axis) to sodium chloride. (C) Normalized integrated emission response ( $\left.F_{G R} / F_{C F P}\right)$ of GR1-CFP in the presence of buffer (Ctrl, $F_{i}$, white bar) and $400 \mathrm{mM}\left(F_{f}\right)$ sodium chloride (black bars). Buffer treated cells were re-equilibrated with buffer only ( $\mathrm{Ctrl}, \mathrm{F}_{\mathrm{i}}$, gray bar), and sodium chloride treated cells were reequilibrated with $400 \mathrm{mM}$ sodium chloride, sodium acetate buffer, or sodium gluconate $\left(\mathrm{F}_{\mathrm{f}}\right.$, gray bars). All spectra were acquired with $E$. coli expressing wtGR-CFP or GR1-CFP in $50 \mathrm{mM}$ sodium acetate buffer at $\mathrm{pH} 5$. Excitation for the rhodopsin was provided at $530 \mathrm{~nm}$, and the emission was collected and integrated from $600-800 \mathrm{~nm}\left(\mathrm{~F}_{\mathrm{GR}}\right)$. Excitation for CFP was provided at $390 \mathrm{~nm}$, and the emission was collected and integrated from 425-560 nm ( $\left.F_{\text {CFP }}\right)$. The average of three biological replicates with standard error of the mean is reported.

Similar to the in vitro measurements, a single site binding model can also be used to fit this titration data, but an improved affinity for chloride $\left(K_{d}=42 \pm 1 \mathrm{mM}\right)$ is observed in cells (Figure S20). This result, although surprising, is in line with the fact that GR1-CFP maintains proper folding when expressed in live and intact membranes and has a larger dynamic range compared to purified GR1. To test the reversibility of the turn-on response 
for GR1-CFP, cells were equilibrated in buffer or $400 \mathrm{mM}$ sodium chloride followed by reequilibration in sodium chloride, sodium acetate buffer, or sodium gluconate (Figure 4C). With this washout experiment, the fluorescence response was restored to baseline levels, indicating that GR1-CFP can sense dynamic changes in extracellular chloride that can readily equilibrate with the periplasmic space. ${ }^{[93]}$ Finally, GR1-CFP was applied the single cell level using confocal fluorescence microscopy. As can be seen in Figure 5, GR1 localizes to the cell membrane, whereas CFP is diffusely localized in the cytosol. Cells expressing GR1-CFP immobilized on agarose pads supplemented with $400 \mathrm{mM}$ sodium chloride display a ca. 1.8-fold turn-on response. Under the same conditions, wtGR-CFP does not show a response (Figures 5, S22).

\section{A}
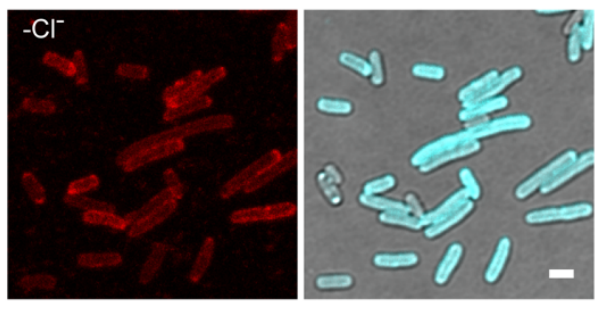

C

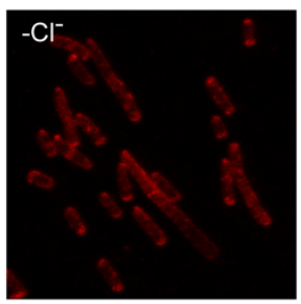

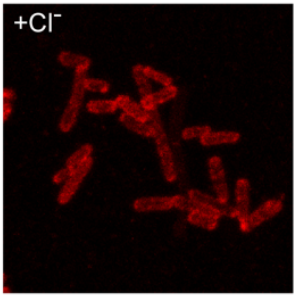

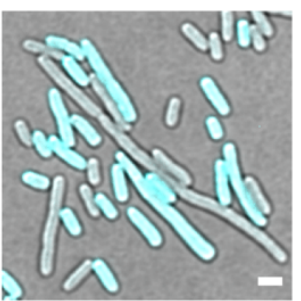

$+\mathrm{Cl}^{-}$

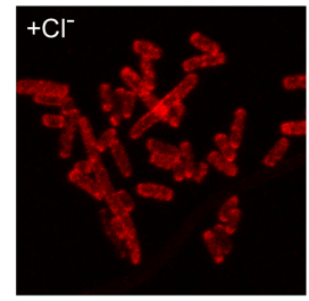

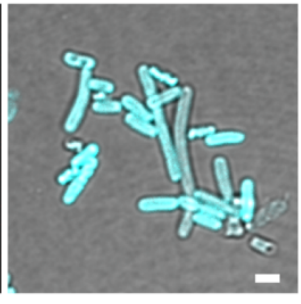

B

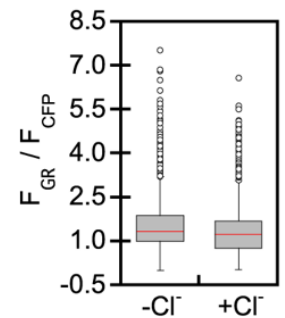

D

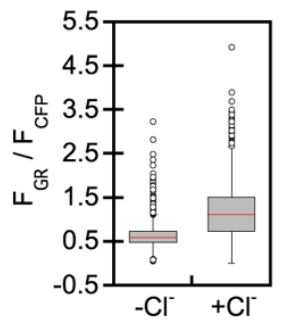

Figure 5. Molecular imaging shows that GR1-CFP is a fluorescent chloride sensor at the single cell level in live $E$. coli. Representative confocal fluorescence microscopy images of $E$. coli expressing (A) wtGR-CFP and (C) GR1-CFP immobilized on 1.5\% agarose pads containing 0 $\mathrm{mM}$ and $400 \mathrm{mM}$ sodium chloride in $50 \mathrm{mM}$ sodium acetate buffer at pH 5 . Images are shown for the rhodopsin in red (left) and an overlay of the CFP in cyan with the transmitted light image (right). Scale bar $=2 \mu \mathrm{m}$. Single cell analysis of the normalized emission response to $400 \mathrm{mM}$ sodium chloride for (B) wtGR-CFP (for $0 \mathrm{mM}$ chloride $\mathrm{n}=2829$ regions of interest (ROIs); for 400 $\mathrm{mM}$ chloride $\mathrm{n}=3818$ ROls) and (D) GR1-CFP (for $0 \mathrm{mM}$ chloride $\mathrm{n}=1890$ ROls; for $400 \mathrm{mM}$ chloride $n=2913$ ROIs). The median fluorescence intensity of the rhodopsin $\left(F_{G R}\right)$ was normalized to the median fluorescence intensity of CFP $\left(F_{C F P}\right)$. Boxplots represent the analysis for all cells in the fields of view with the lower and upper quartile data enclosed by the gray box. The median values are indicated by the red line, and the minimum and maximum values for each data set are indicated by the lines extending below and above the gray box. Data points that fall outside of these parameters are considered outliers and are shown as open circles. At least four different fields were analyzed for each biological replicate $(n=3)$.

Finally, since $w t G R$ is a light-activated outward proton pump, ion pumping assays were conducted in $400 \mathrm{mM}$ sodium chloride. White light LED illumination of $E$. coli expressing $w t G R-C F P$ results in a time-dependent decrease in the extracellular $\mathrm{pH}$ (Figure S23). Upon removal of LED illumination, the extracellular $\mathrm{pH}$ is restored to baseline levels. 
Moreover, treatment with the protonophore carbonyl cyanide 3-chlorophenylhydrazone (30 $\mu \mathrm{M}$ CCCP) serves as a control to abolish the proton gradient and equalize the membrane potential, thus validating our experimental setup. ${ }^{[94]}$ Under the same conditions, GR1-CFP does not pump protons; these observations are in line with dyebased proton-pumping assays. ${ }^{[88]}$ We can also conclude that GR1-CFP is not a lightactivated chloride pump because the extracellular $\mathrm{pH}$ does not change as observed in other CPRs and engineered PPRs. ${ }^{[65,94-97]}$ Furthermore, since PPRs can also be used as fluorescent indicators of membrane potential, chloride titrations were carried out at $\mathrm{pH} 5$ in the presence of CCCP. ${ }^{[71]}$ Even though CCCP treatment uncouples the membrane potential, as independently confirmed with a commercially available dye, the fluorescence response of both wtGR-CFP and GR1-CFP are not affected (Figures S24-S25). ${ }^{[98]}$ Taken together, our data show that wtGR-CFP can be converted into a non-pumping, ratiometric fluorescent sensor for chloride that is independent of membrane potential; thus, allowing for the reversible detection of chloride in exogenously supplemented live E. coli. Our discovery establishes that rhodopsins can be a new platform to build fluorescent sensors for studying chloride in living cells and provides an opportunity at the intersection of protein engineering and molecular recognition to create biological supramolecular hosts for chloride.

\section{Conclusion}

From a molecular perspective, naturally occurring CPRs combine the hydrophobic effect with multivalent, cooperative interactions to achieve anion recognition in water. Drawing on these design principles, we showcase how protein engineering can be used to create a chloride binding site in the cyanobacterial proton-pump Gloeobacter violaceus rhodopsin (wtGR), resulting in a non-pumping, $\mathrm{pH}$-dependent, turn-on fluorescent sensor for chloride (GR1) in detergent micelles and live E. coli. This non-natural function was unlocked by substituting the aspartate counterion to the protonated SBC with valine at position 121, which to date has not been identified in the rhodopsin family. In vitro characterization shows that chloride binding tunes the $\mathrm{pK}$ a of the SBC towards the protonated, fluorescent state to generate a $\mathrm{pH}$-dependent response to not only chloride, but also bromide, iodide, and nitrate. Based on these spectroscopic data, it is likely that chloride forms an electrostatic interaction with the protonated SBC in the excited state. Future investigations with time-resolved spectroscopy will be used to confirm this mechanism. ${ }^{[72,73]}$ Moreover, bulk and single cell fluorescence measurements of $E$. coli expressing the GR1-CFP fusion show that GR1 does not sense membrane potential but instead provides a reversible, ratiometric readout of chloride in living cells. Looking forward, we will utilize directed evolution to improve the dynamic range, sensitivity, and operational $\mathrm{pH}$ of GR1. We envision that rhodopsins and other pigment-containing proteins can serve as scaffolds to create functional tools to study chloride in living systems and, more broadly, serve as biological supramolecular hosts to advance our fundamental understanding of anion recognition in aqueous systems. 


\section{Methods}

General. All reagents and chemicals were purchased from Sigma-Aldrich, Thermo Fisher Scientific, or VWR and were used as received unless otherwise stated.

Design and cloning of plasmids, site-saturation mutagenesis library, and point mutations. The DNA sequence encoding the Gloeobacter violaceus rhodopsin (GR, UniProt ID: Q7NP59) was used as previously described but with T121. ${ }^{[88]}$ This gene was synthesized and cloned into the pET-21a $(+)$ vector between the Nde1 and Not1 restriction sites (GenScript, Figure S1A). For the GR T121-CFP construct, the DNA sequence encoding the cyan fluorescent protein from Aequorea victoria (CFP, UniProt ID: P42212) was used as previously described. ${ }^{[88]}$ This gene synthesized and cloned into the GR T121 pET-21a(+) construct between the Not1 and Xho1 restriction sites (GenScript, Figure S1B).

The site-saturation mutagenesis (SSM) library was generated using the GR T121-CFP construct as previously described. ${ }^{[48,99]}$ The forward primers were 37 bases long with the degenerate bases NDT, VHG, or TGG at position 121, and the reverse primer was 34 bases long that contained 18 overlapping bases with the forward primer (Sigma-Aldrich, Table S1). A solution of the three forward primers were combined in a 12:9:1 ratio. The forward and reverse primers were each diluted to a final concentration of $10 \mu \mathrm{M}$ with autoclaved water. The polymerase chain reaction (PCR) was carried out with the Phusion High Fidelity PCR Kit (New England Biolabs) according to the manufacturer's instructions with $1 \mu \mathrm{L}$ of template plasmid from a $10 \mathrm{ng} / \mu \mathrm{L}$ stock solution, $1.5 \mu \mathrm{L}$ of the forward and reverse primers from $10 \mu \mathrm{M}$ stock solutions, $0.5 \mu \mathrm{L}$ of dNTPs from a $10 \mathrm{mM}$ stock solution, $0.5 \mu \mathrm{L}$ of dimethyl sulfoxide (DMSO), $5 \mu \mathrm{L}$ of Phusion GC buffer, $0.25 \mu \mathrm{L}$ of Phusion DNA polymerase, and $9.75 \mu \mathrm{L}$ of autoclave water to a final volume of $25 \mu \mathrm{L}$. The PCR conditions are outlined in Table S2. After the PCR, the reaction mixture was treated with $1 \mu \mathrm{L}$ Dpn 1 (New England Biolabs) for $2 \mathrm{~h}$ at $37^{\circ} \mathrm{C}$ to remove the template DNA. The PCR product was then purified with agarose gel electrophoresis and extracted with the Zymoclean Gel DNA Recovery Kit (Zymo Research) according to the manufacturer's instructions. Ten microliters of the purified PCR product was ligated using the Gibson Assembly Master Mix (New England Biolabs), followed by cleanup with the DNA Clean \& Concentrator Kit (Zymo Research) according manufacturers' instructions. One microliter of the resulting DNA was used to transform E. cloni EXPRESS BL21(DE3) Competent Cells (Lucigen) by electroporation (Bio-Rad Laboratories). The constructs for wild-type (wt) GR (D121) and the GR1 variant (V121) were prepared with the pET-21a(+) GR T121 construct. The forward primers were 37 bases long with the mutation site, and the same reverse primer described above was used (Table S1). The PCR conditions and downstream processing steps were carried out as described above (Table S3).

Following electroporation, E. cloni were plated on Luria Broth (LB) agar plates containing $100 \mu \mathrm{g} / \mathrm{mL}$ ampicillin. To verify the sequences of the point mutants, colonies were picked into $5 \mathrm{~mL}$ of LB containing $100 \mu \mathrm{g} / \mathrm{mL}$ ampicillin in $14 \mathrm{~mL}$ culture tubes (Corning) and incubated overnight (New Brunswick Innova $42 \mathrm{R}$ Shaker) at $37^{\circ} \mathrm{C}$ with shaking at 250 $\mathrm{rpm}$. The following day, cells were collected by centrifugation at $3,000 \mathrm{~g}$ for $5 \mathrm{~min}$ (Allegra 
$\mathrm{X}-14 \mathrm{R}$, Beckman Coulter) and stored at $-20^{\circ} \mathrm{C}$. The plasmid DNA was isolated with the QIAprep Spin Miniprep Kit (Qiagen) and sequenced to identify the correct clone (Eurofins Scientific).

SSM library expression, screening, and validation. The methods described here were adapted from a previously reported procedure. ${ }^{[88]}$ Eighty-eight single colonies of $E$. cloni transformed with the SSM library were picked into $300 \mu \mathrm{L}$ of LB containing $100 \mu \mathrm{g} / \mathrm{mL}$ ampicillin in a 96-well deep well plate (Greiner Bio-One) and sealed with an Easy App microporous film (USA Scientific). The 96-well deep well plate was incubated overnight at $37^{\circ} \mathrm{C}$ with shaking at $230 \mathrm{rpm}$. The following day, each well of a 96-well deep well plate was filled with $950 \mu \mathrm{L}$ of LB containing $100 \mu \mathrm{g} / \mathrm{mL}$ ampicillin and inoculated with 50 $\mu \mathrm{L}$ of the overnight culture using a Biomek NXP liquid handler (Beckman Coulter). After 2 $\mathrm{h}$ and $15 \mathrm{~min}$ of incubation at $30^{\circ} \mathrm{C}$ with shaking at $230 \mathrm{rpm}$, protein expression was induced with the addition of $50 \mu \mathrm{L}$ of LB containing $100 \mu \mathrm{g} / \mathrm{mL}$ ampicillin, $105 \mathrm{mM}$ isopropyl beta-D-thiogalactopyranoside (IPTG, Gold Biotechnology) and $2.1 \mathrm{mM}$ alltrans-retinal (ATR, Sigma-Aldrich) to each well for a final concentration of $500 \mu \mathrm{M}$ IPTG and $10 \mu \mathrm{M}$ ATR. Protein expression was carried out at $30^{\circ} \mathrm{C}$ with shaking at $230 \mathrm{rpm}$. After $4 \mathrm{~h}$, the cells were harvested by centrifugation at $4,000 \mathrm{~g}$ for 5 min (Allegra X-14R, Beckman Coulter). Using the liquid handler, the cell pellets were resuspended in $500 \mu \mathrm{L}$ of $50 \mathrm{mM}$ sodium acetate buffer at $\mathrm{pH} 5,50 \mathrm{mM}$ sodium phosphate buffer at $\mathrm{pH} 6$, or 50 $\mathrm{mM}$ sodium phosphate buffer at $\mathrm{pH} 7$, and $175 \mu \mathrm{L}$ of the cell suspension was transferred to a clear 96-well microtiter plate (Caplugs) for plate reader measurements. Excitation for the rhodopsin was provided at $530 \mathrm{~nm}$ with a 10-nm bandwidth, and the emission was collected from 580-760 nm with a 20-nm bandwidth, a 10-nm step size, 25 flashes, and gain of 100 (Spark 20M, Tecan). Excitation for CFP was provided at $425 \mathrm{~nm}$ with a 10$\mathrm{nm}$ bandwidth, and the emission was collected from $470-510 \mathrm{~nm}$ with a $20-\mathrm{nm}$ bandwidth, a 10-nm step size, 25 flashes, and gain of 55 . Following these emission scans, $25 \mu \mathrm{L}$ of a $3.2 \mathrm{M}$ sodium chloride stock solution in water was added to each well using a multichannel pipette (Eppendorf) for a final concentration of $400 \mathrm{mM}$ sodium chloride. Then, the 96-well plate was shaken for $5 \mathrm{~s}$ and processed for plate reader measurements as described above.

Variants that showed an increase in fluorescence intensity in the presence of sodium chloride were streaked onto fresh LB agar plates containing $100 \mu \mathrm{g} / \mathrm{mL}$ ampicillin to isolate single colonies for rescreening. Eight single colonies of each variant were picked into $5 \mathrm{~mL}$ of LB containing $100 \mu \mathrm{g} / \mathrm{mL}$ ampicillin in $14 \mathrm{~mL}$ culture tubes and incubated overnight at $37^{\circ} \mathrm{C}$ with shaking at $250 \mathrm{rpm}$. The following day, the overnight cultures were diluted 1:20 (v/v) into $3 \mathrm{~mL}$ of LB containing $100 \mu \mathrm{g} / \mathrm{mL}$ ampicillin in $14 \mathrm{~mL}$ culture tubes and incubated at $30{ }^{\circ} \mathrm{C}$ with shaking at $250 \mathrm{rpm}$. After $2.5 \mathrm{~h}$, protein expression was induced with $15 \mu \mathrm{L}$ of $100 \mathrm{mM} \mathrm{IPTG}$ and $15 \mu \mathrm{L}$ of $2 \mathrm{mM}$ ATR for a final concentration of $500 \mu \mathrm{M}$ IPTG and $10 \mu \mathrm{M}$ ATR and incubated at $30{ }^{\circ} \mathrm{C}$ for $4 \mathrm{~h}$ with shaking at $250 \mathrm{rpm}$. For a negative control, three single colonies of GR1-CFP were grown as described above but not induced (Figure S2). The cell pellets were collected by centrifugation at $2,500 \mathrm{~g}$ for $5 \mathrm{~min}$ (5810 R, Eppendorf) and resuspended in $200 \mu \mathrm{L}$ of $50 \mathrm{mM}$ sodium acetate buffer at $\mathrm{pH} 5$. For the plate reader rescreen, $25 \mu \mathrm{L}$ of the cell suspension for each biological replicate was transferred to two separate wells of a 96-well microtiter plate 
containing $175 \mu \mathrm{L}$ of $50 \mathrm{mM}$ sodium acetate buffer at $\mathrm{pH} 5$ or buffer containing $457 \mathrm{mM}$ sodium chloride for a final concentration of $400 \mathrm{mM}$ sodium chloride. Excitation scans were acquired to determine the optimal excitation wavelength for the rhodopsin emission at $710 \mathrm{~nm}$ with a 20-nm bandwidth. Excitation spectra were collected from 500-650 nm with a 10-nm bandwidth, a 5-nm step size, 30 flashes, and gain of 100 (Spark 10M, Tecan). Consistent with the SSM library screening methods, the rhodopsin was excited at $530 \mathrm{~nm}$ with a 10-nm bandwidth, and the emission was collected from 600-800 nm with a $20-\mathrm{nm}$ bandwidth, a 5-nm step size, 30 flashes, and gain of 100. The CFP was excited at $390 \mathrm{~nm}$ with a 10-nm bandwidth, and the emission was collected from 425$560 \mathrm{~nm}$ with a $20-\mathrm{nm}$ bandwidth, a 5-nm step size, 30 flashes, and gain of 55 . The rhodopsin and CFP emissions were integrated from 600-800 nm (FGR) and 425-560 nm $\left(F_{C F P}\right)$, respectively, using the trapz function in MATLAB R2017a (MathWorks). For each variant, the average emission response of eight biological replicates with standard error of the mean is reported (Figures S4, S6-S9).

Rhodopsin family sequence alignment. The amino acid sequence for wtGR (UniProt ID: Q7NP59, residues 45-270) was used to search the UniProt Knowledgebase for homologous proteins in the rhodopsin family using the HMMER webserver v2.41.1 (www.ebi.ac.uk/Tools/hmmer). ${ }^{[100,101]}$ The expectation value (E) threshold was set to 0.01 to filter and obtain 6,906 protein sequences that are similar to wtGR. Next, we excluded protein sequences containing consecutive gaps, in the alignment, longer than $20 \%$ of the protein length ( $>45$ consecutive gaps) to reduce the noise from partial sequences. The resulting 3,285 protein sequences were aligned using the Clustal Omega software v1.2.4. The amino acid diversity at the counterion position in wtGR (D121) was analyzed and is presented in Figure S4C.

$w t G R$ and GR1 chloride titrations in live E. coli. Three-3 $\mathrm{mL}$ cultures of E. cloni containing the wtGR and GR1 only constructs were expressed at $30^{\circ} \mathrm{C}$ as described above. After $4 \mathrm{~h}$, the expression cultures were collected by centrifugation $3,000 \mathrm{~g}$ for 5 min (Allegra X-14R, Beckman Coulter) and resuspended in $200 \mu \mathrm{L}$ of $50 \mathrm{mM}$ sodium acetate buffer at $\mathrm{pH} 5$. In a 96-well plate, $175 \mu \mathrm{L}$ of the cell suspension was diluted with $25 \mu \mathrm{L}$ of $0 \mathrm{M}$ or 3 . $2 \mathrm{M}$ sodium chloride in water to a final concentration of $0 \mathrm{mM}$ and 400 $\mathrm{mM}$ sodium chloride. Excitation was provided at $530 \mathrm{~nm}$ with a $10-\mathrm{nm}$ bandwidth, and the emission was collected from 600-760 nm with a 20-nm bandwidth, a $5 \mathrm{~nm}$-step size, 25 flashes and a gain of 100 (Spark 10M, Tecan). The average of three technical replicates with standard error of the mean is reported (Figure S10).

wtGR-CFP and GR1-CFP pH profiles in live E. coli. Three single colonies of E. cloni containing the wtGR-CFP and GR1-CFP plasmids were picked into $5 \mathrm{~mL}$ of LB containing $100 \mu \mathrm{g} / \mathrm{mL}$ ampicillin and incubated overnight at $37^{\circ} \mathrm{C}$ as described above. The next day, the overnight cultures were diluted 1:20 (v/v) into $25 \mathrm{~mL}$ of LB containing $100 \mu \mathrm{g} / \mathrm{mL}$ ampicillin in $125 \mathrm{~mL}$ baffled flasks and incubated at $30^{\circ} \mathrm{C}$ with shaking at $250 \mathrm{rpm}$. After $2.5 \mathrm{~h}$, protein expression was induced with $119 \mu \mathrm{L}$ of $105 \mathrm{mM}$ IPTG and $20.8 \mu \mathrm{L}$ of 12 $\mathrm{mM}$ ATR to a final concentration of $500 \mu \mathrm{M}$ IPTG and $10 \mu \mathrm{M}$ ATR and incubated at $30^{\circ} \mathrm{C}$ with shaking at $250 \mathrm{rpm}$. After $4 \mathrm{~h}, 6 \mathrm{~mL}$ of each expression culture was collected by centrifugation $2,500 \mathrm{~g}$ for $5 \mathrm{~min}$ (5810 R, Eppendorf), washed $3 \mathrm{~mL}$ of $50 \mathrm{mM}$ sodium 
acetate buffer at $\mathrm{pH} 5,50 \mathrm{mM}$ sodium phosphate buffer at $\mathrm{pH} 6$, or $50 \mathrm{mM}$ sodium phosphate buffer at $\mathrm{pH} 7$, and resuspended in $400 \mu \mathrm{L}$ of the corresponding buffer. In a 96-well plate, $25 \mu \mathrm{L}$ of the cell suspension was diluted with $175 \mu \mathrm{L}$ of the corresponding buffer containing $0 \mathrm{mM}$ or $457 \mathrm{mM}$ sodium chloride to a final concentration of $0 \mathrm{mM}$ and $400 \mathrm{mM}$ sodium chloride. Excitation scans were acquired for the rhodopsin emission at $710 \mathrm{~nm}$ with a 20-nm bandwidth. Excitation spectra were collected from 500-650 nm with a 10-nm bandwidth, a 5-nm step size, 30 flashes, and gain of 100. The rhodopsin was excited at $530 \mathrm{~nm}$ with a 10-nm bandwidth, and the emission was collected from 600$800 \mathrm{~nm}$ with a 20-nm bandwidth, a 5-nm step size, 30 flashes, and gain of 100 . The CFP was excited at $390 \mathrm{~nm}$ with a 10-nm bandwidth, and the emission was collected from 425-560 nm with a 20-nm bandwidth, a 5-nm step size, 30 flashes, and gain of 55 (Spark $10 \mathrm{M}$, Tecan). The rhodopsin and CFP emissions were integrated from 600-800 nm ( $\left.F_{G R}\right)$ and 425-560 $\mathrm{nm}$ ( $\mathrm{F}_{\mathrm{CFP}}$ ), respectively, using the trapz function in MATLAB R2017a (MathWorks). The average of three biological replicates with standard error of the mean is reported (Figures 2, S3, S5).

Large-scale protein expression and purification. For large-scale protein expression, E. cloni were transformed as described above with plasmids encoding wtGR and GR1. Single colonies were picked into $50 \mathrm{~mL} 2 x Y T$ media containing $50 \mu \mathrm{g} / \mathrm{mL}$ ampicillin in 250 $\mathrm{mL}$ baffled flasks and incubated overnight at $37^{\circ} \mathrm{C}$ with shaking at $230 \mathrm{rpm}$. The following day, cultures were diluted 1:40 (v/v) into $1 \mathrm{~L}$ of $2 x Y T$ containing $50 \mu \mathrm{g} / \mathrm{mL}$ ampicillin in 2.8 $\mathrm{L}$ baffled flasks and incubated at $37^{\circ} \mathrm{C}$ until the $\mathrm{OD}_{600}$ reached $\sim 0.6-0.8$. The flasks were then cooled on ice for $30 \mathrm{~min}$. Following this, protein expression was induced with the addition of $952 \mu \mathrm{L}$ of $105 \mathrm{mM}$ IPTG and $833 \mu \mathrm{L}$ of $12 \mathrm{mM}$ ATR to a final concentration of $100 \mu \mathrm{M}$ IPTG and $10 \mu \mathrm{M}$ ATR and incubated overnight at $18{ }^{\circ} \mathrm{C}$ with shaking at $230 \mathrm{rpm}$. The following day, the cells were collected by centrifugation at $3,000 \mathrm{~g}(5810 \mathrm{R}$, Eppendorf) for $30 \mathrm{~min}$ at $4{ }^{\circ} \mathrm{C}$ and stored at $-20{ }^{\circ} \mathrm{C}$ until further use.

The following steps were carried out at $4{ }^{\circ} \mathrm{C}$. The frozen cell pellet was thawed and resuspended in a 1:5 (w/v) of pre-chilled $20 \mathrm{mM}$ Tris buffer at $\mathrm{pH} 7.5$ containing $200 \mathrm{mM}$ sodium chloride, $5 \mathrm{mM}$ magnesium chloride, $30 \mu \mathrm{g} / \mathrm{mL}$ deoxyribonuclease I, and two cOmplete Protease Inhibitor Tablets (Roche) and homogenized with stiring in a foiled beaker. Cell lysis was carried out with sonication at $40 \%$ amplitude, $15 \mathrm{~s}$ pulse on, and $45 \mathrm{~s}$ pulse off for $10 \mathrm{~min}$ (Q500, QSonica). The cell debris was collected by centrifugation at 3,000 $\mathrm{g}$ for $30 \mathrm{~min}$ ( $5810 \mathrm{R}$, Eppendorf). The membrane fraction was isolated by ultracentrifugation at 159,200g (Sorvall WX 80+, Thermo Fisher Scientific) for $1 \mathrm{~h}$, resuspended in $15 \mathrm{~mL}$ of $20 \mathrm{mM}$ Tris buffer at $\mathrm{pH} 7.5$ containing $200 \mathrm{mM}$ sodium chloride and $10 \%$ glycerol, homogenized using a tissue grinder (Wheaton), and stored at $-80^{\circ} \mathrm{C}$ until further use.

The following day, the isolated cell membrane was thawed on ice for 30 min and solubilized with vigorous stirring in $35 \mathrm{~mL}$ of $20 \mathrm{mM}$ Tris buffer at $\mathrm{pH} 7.5$ containing 300 $\mathrm{mM}$ sodium chloride, $1 \% \mathrm{n}$-Dodecyl- $\beta$-D-Maltopyranoside (DDM, w/v, Anatrace), and one cOmplete Protease Inhibitor Tablet. Insoluble debris was collected by ultracentrifugation at 159,200g (Sorvall WX 80+, Thermo Fisher Scientific) for 20 min, and the supernatant was loaded onto a $90 \mathrm{~mL}$ sample loop (Bio-Rad Laboratories). Protein purification was 
carried out with the NGC Quest 10 Chromatography System (Bio-Rad Laboratories). A 5$\mathrm{mL}$ nickel nitrilotriacetic acid (Ni-NTA) affinity column (HisTrap, GE Healthcare) was equilibrated with 5 column volumes (CV) of $20 \mathrm{mM}$ Tris running buffer at $\mathrm{pH} 7.5$ containing $300 \mathrm{mM}$ sodium chloride, $25 \mathrm{mM}$ imidazole, and $0.02 \%$ DDM (w/v). The protein sample was loaded onto the Ni-NTA column with a $5 \mathrm{~mL} / \mathrm{min}$ flow rate, eluted with a $0-100 \%$ gradient of the running buffer and the $20 \mathrm{mM}$ Tris elution buffer at $\mathrm{pH} 7.5$ containing 300 $\mathrm{mM}$ sodium chloride, $500 \mathrm{mM}$ imidazole, and $0.02 \%$ DDM (w/v) over $20 \mathrm{CV}$, and washed with $5 \mathrm{CV}$ of the elution buffer. Fractions with an absorbance at $570 \mathrm{~nm}$ were combined and loaded onto a HiPrep 26/10 desalting column (GE Healthcare) pre-equilibrated with $50 \mathrm{mM}$ sodium acetate buffer at $\mathrm{pH} 5$ containing $0.05 \%$ DDM $(\mathrm{w} / \mathrm{v})$. Protein fractions were pooled and concentrated using an Amicon Ultra-15 Centrifugal Filter Unit with a $10 \mathrm{kDa}$ molecular weight cut-off (MilliporeSigma), aliquoted, flash frozen in powdered dry ice, and stored at $-80^{\circ} \mathrm{C}$ for assays described below.

SDS-PAGE and Coomassie staining. The purity of purified wtGR and GR1 was evaluated by sodium dodecyl sulfate polyacrylamide gel electrophoresis (SDS-PAGE) using a previously reported procedure with the modification that samples were heated in Laemmli sample buffer at $37^{\circ} \mathrm{C}$ for $10 \mathrm{~min}$ (Figure S11). ${ }^{[48]}$

General spectroscopic materials and methods. Absorbance and fluorescence spectra were collected using the Agilent Cary 7000 Spectrophotometer and the Horiba Fluorolog3 , respectively, as previously reported. ${ }^{[48]}$ Measurements were acquired with a $0.2-\mathrm{cm} \mathrm{x}$ 1 -cm quartz cuvette $(0.4 \mathrm{~mL}$, Hellma USA).

Extinction coefficient and quantum yield determination with purified proteins. Aliquots of wtGR and GR1 in $50 \mathrm{mM}$ sodium acetate buffer with $0.05 \% \mathrm{DDM}$ at pH 5 were first diluted to $\sim 5 \mu \mathrm{M}$ with $50 \mathrm{mM}$ sodium acetate buffer at $\mathrm{pH} 5$ containing $600 \mathrm{mM}$ sodium gluconate. Protein concentrations were determined using the Beer-Lambert Law by dividing the wtGR and GR1 absorbance values at $550 \mathrm{~nm}$ and $565 \mathrm{~nm}$, respectively, by their molar extinction coefficients and the pathlength of $1 \mathrm{~cm}$. The molar extinction coefficients were determined using a previously reported procedure. ${ }^{102]}$ Briefly, a $2.7 \mathrm{M}$ hydroxylamine stock solution was prepared fresh in deionized water and $148 \mu \mathrm{L}$ of this solution was added to $252 \mu \mathrm{L}$ of the diluted protein stock solution for a final concentration of $1 \mathrm{M}$ hydroxylamine and $\sim 3 \mu \mathrm{M}$ protein in a $0.4 \mathrm{~mL}$ quartz cuvette to displace the covalently bound SBC. Absorbance spectra were collected from 300-700 nm with a 2$\mathrm{nm}$ bandwidth and a 5-nm step size every $10 \mathrm{~min}$ for $12 \mathrm{~h}$. The change in absorbance of free ATR at $360 \mathrm{~nm}\left(\triangle \mathrm{Abs}_{\mathrm{ATR}}\right)$ was plotted versus the change in absorbance of the rhodopsin at $550 \mathrm{~nm}$ for $w t \mathrm{GR}$ or $565 \mathrm{~nm}$ for GR1 ( $\triangle \mathrm{Abs}$ GR) over time and fitted to a linear fit model: $y=m x+b$, where the $m$ is the slope variable and is equal to $\triangle$ Abs $_{G R} / \triangle$ Abs $_{A T R}$. The molar extinction coefficients for wtGR and GR1 ( $\left.\varepsilon_{G R}\right)$ were determined using the following equation: $\varepsilon_{G R}=\Delta \mathrm{Abs}_{\mathrm{GR}} / \Delta \mathrm{AbS}_{\mathrm{ATR}}{ }^{*} \varepsilon_{\mathrm{ATR}}$ where the molar extinction coefficient for $\operatorname{ATR}\left(\varepsilon_{\text {ATR }}\right)$ in ethanol is $43,400 \mathrm{M}^{-1} \mathrm{x} \mathrm{cm}^{-1} .{ }^{[103]}$ The average of three technical replicates with standard error of the mean is reported (Figure S12).

The wtGR and GR1 quantum yield experiments were carried out in the absence and presence of $400 \mathrm{mM}$ sodium chloride with respect to rhodamine 101 inner salt in methanol 
$(\Phi=1.0)$ as a reference. ${ }^{[104]}$ Serial dilutions of $w t G R$ and GR1 were prepared in $50 \mathrm{mM}$ sodium acetate buffer at $\mathrm{pH} 5$ containing $600 \mathrm{mM}$ sodium gluconate, and serial dilutions of rhodamine 101 inner salt were prepared in methanol. Each sample was transferred to a 96-well half area plate (Greiner Bio-One) for plate reader measurements. Absorbance spectra were collected from $400-750 \mathrm{~nm}$ with a 5-nm step size, and the absorbance values were kept between 0 and 0.3 . Excitation was provided at $530 \mathrm{~nm}$ with a $10-\mathrm{nm}$ bandwidth, and the emission was collected from $565-800 \mathrm{~nm}$ with a 20-nm bandwidth, a 5 -nm step size, 30 flashes, and gain of 58 (Spark 10M, Tecan). The emission of the rhodopsins and rhodamine 101 inner salt were integrated from $565-800 \mathrm{~nm}$ using the trapz function in MATLAB. A standard curve was generated for each sample by plotting the absorbance value at $565 \mathrm{~nm}$ versus the integrated emission using the linear fit model: $y=m x+b$, where $m$ is the slope variable $\left(R^{2}>0.99\right)$. The quantum yields for wtGR and GR1 were calculated using the equation: $F_{G R}=\left(m_{G R} / m_{r e f}\right)\left(\eta_{G R}{ }^{2} / \eta_{r e f}{ }^{2}\right)$ where $\eta$ is the refractive index values for water $(\eta=1.770)$ and methanol $(\eta=1.765)$ (Figure $S 14) .{ }^{[105,106]}$ The average of three technical replicates with standard error of the mean is reported (Figure S14).

Chloride titrations with purified protein. Aliquots of purified wtGR and GR1 in $50 \mathrm{mM}$ sodium acetate buffer at $\mathrm{pH} 5$ with $0.05 \%$ DDM were diluted into $50 \mathrm{M}$ sodium acetate buffer at $\mathrm{pH} 5$ containing $1.2 \mathrm{M}$ sodium gluconate to a final concentration of $\sim 6 \mu \mathrm{M}$ protein and $600 \mathrm{mM}$ sodium gluconate. The protein stock solution was further diluted 1:1 (v/v) into $50 \mathrm{mM}$ sodium acetate buffer at pH 5 containing $600 \mathrm{mM}$ sodium gluconate and 0 , $25,50,100,200,400,600$, and $800 \mathrm{mM}$ sodium chloride for a final concentration of $\sim 3$ $\mu \mathrm{M}$ protein and $0,12.5,25,50,100,200,300$, and $400 \mathrm{mM}$ sodium chloride. Excitation spectra were collected from $475-650 \mathrm{~nm}$ with a $14-\mathrm{nm}$ bandpass and a 5-nm step size for the rhodopsin emission at $710 \mathrm{~nm}$ with a 14-nm bandpass. The excitation for wtGR and GR1 was provided at $530 \mathrm{~nm}$ with a 14-nm bandpass, and the emission spectra were collected from 560-800 $\mathrm{nm}$ with a 14-nm bandpass and a 5-nm step size. The rhodopsin emission was integrated from 560-800 nm using the trapz function in MATLAB. The integrated emission response of GR1 defined as $F=\left(F_{\text {obs }}-F_{\min }\right) /\left(F_{\max }-F_{\min }\right)$ was plotted versus the $\left[\mathrm{Cl}^{-}\right]$in Kaleidagraph v4.5 (Synergy Software) to determine the apparent dissociation constant $\left(K_{d}\right)$. The $K_{d}$ was calculated using the following equation: $\mathrm{F}=\left[\mathrm{Cl}^{-}\right] /$ $\left(K_{d}+\left[\mathrm{Cl}^{-}\right]\right)$, where $F_{\text {obs }}$ is the observed fluorescence and $F_{\min }$ and $F_{\max }$ are the fluorescence intensities at $0 \mathrm{mM}$ and $400 \mathrm{mM}$ sodium chloride, respectively. The average of three technical replicates with standard error of the mean is reported (Figures 3, S13, S15).

Anion selectivity with purified proteins. Aliquots of purified GR1 in $50 \mathrm{mM}$ sodium acetate buffer at $\mathrm{pH} 5$ with $0.05 \%$ DDM were diluted into $50 \mathrm{M}$ sodium acetate buffer at $\mathrm{pH} 5$ containing $1.2 \mathrm{M}$ sodium gluconate to a final concentration of $\sim 6 \mu \mathrm{M}$ protein and 600 $\mathrm{mM}$ sodium gluconate. The protein stock solution was further diluted 1:1 (v/v) into $50 \mathrm{mM}$ sodium acetate buffer at $\mathrm{pH} 5$ containing $600 \mathrm{mM}$ sodium gluconate and/or $800 \mathrm{mM}$ sodium chloride, sodium bromide, sodium iodide, sodium nitrate, sodium dihydrogen phosphate, or sodium hydrogen sulfate to a final concentration of $\sim 3 \mu \mathrm{M}$ protein, $0 \mathrm{mM}$, and $400 \mathrm{mM}$ of the anion. The excitation for GR1 was provided at $530 \mathrm{~nm}$ with a 14-nm bandpass, and the emission was collected from $560-800 \mathrm{~nm}$ with a 14-nm bandpass and 
a 5-nm step size. The rhodopsin emission was integrated from $560-800 \mathrm{~nm}$ using the trapz function in MATLAB. The average emission response for three technical replicates with standard error of the mean is reported (Figures 3C, S16).

Determination of the Schiff base $p K_{\mathrm{a}}$ with purified proteins. Aliquots of purified wtGR and GR1 in $50 \mathrm{mM}$ sodium acetate buffer at $\mathrm{pH} 5$ with $0.05 \%$ DDM were diluted into a mixture of six-buffers to a final concentration of $\sim 3 \mu \mathrm{M}$ protein. The mixture of six buffers contained $5 \mathrm{mM}$ bicine, $5 \mathrm{mM} \mathrm{N}$-cyclohexyl-3-aminopropanesulfonic acid, $5 \mathrm{mM} \mathrm{N}$ cyclohexyl-2-aminoethanesulfonic acid, $5 \mathrm{mM}$ 2-(N-morpholino)ethanesulfonic acid, 5 $\mathrm{mM} 3-(\mathrm{N}$-morpholino)propanesulfonic acid, and $5 \mathrm{mM}$ sodium citrate, and $600 \mathrm{mM}$ sodium gluconate starting at $\mathrm{pH} 4{ }^{\left[{ }^{[102]}\right.}$ The $\mathrm{pH}$ was adjusted then by adding $1 \mu \mathrm{L}$ of $1 \mathrm{M}$ $\mathrm{NaOH}$ to $1 \mathrm{~mL}$ of the protein solution. Excitation was provided at $530 \mathrm{~nm}$ with a 14-nm bandpass, the emission was collected from $560-800 \mathrm{~nm}$ with a $14-\mathrm{nm}$ bandpass and a 5 -nm step size. The rhodopsin emission was integrated from 560-800 nm using the trapz function in MATLAB. The relative emission response was plotted versus $\mathrm{pH}$ in Kaleidagraph $\mathrm{v} 4.5$ and fitted to the Henderson-Hasselbach equation to determine the SBC $\mathrm{p} K_{\mathrm{a}}$. The average integrated emission for three technical replicates with standard error of the mean is reported (Figures S17-S18).

General protein expression protocol and plate reader settings for assays with live E. coli. E. cloni were transformed with plasmids encoding wtGR-CFP and GR1-CFP as described above. Single colonies were picked into $5 \mathrm{~mL}$ of LB containing $100 \mu \mathrm{g} / \mathrm{mL}$ ampicillin in $14 \mathrm{~mL}$ culture tubes and incubated overnight at $37^{\circ} \mathrm{C}$ with shaking at 250 rpm. The next day, overnight cultures were diluted 1:20 (v/v) in either $3 \mathrm{~mL}$ of LB containing $50 \mu \mathrm{g} / \mathrm{mL}$ ampicillin in $14 \mathrm{~mL}$ culture tubes or $25 \mathrm{~mL}$ LB containing $50 \mu \mathrm{g} / \mathrm{mL}$ ampicillin in $125 \mathrm{~mL}$ baffled flasks. The cultures were incubated at $30^{\circ} \mathrm{C}$ with shaking at $250 \mathrm{rpm}$. After $2.5 \mathrm{~h}$, protein expression was induced with the addition of $15 \mu \mathrm{L}$ of 100 $\mathrm{mM}$ IPTG and $15 \mu \mathrm{L}$ of $2 \mathrm{mM}$ ATR in $3 \mathrm{~mL}$ LB or $119 \mu \mathrm{L}$ of $105 \mathrm{mM} \mathrm{IPTG}$ and $20.8 \mu \mathrm{L}$ of $12 \mathrm{mM}$ ATR in $25 \mathrm{~mL}$ LB to a final concentration of $500 \mu \mathrm{M} \mathrm{IPTG}$ and $10 \mu \mathrm{M}$ ATR. Protein expression was carried out at $30^{\circ} \mathrm{C}$ for $4 \mathrm{~h}$ with shaking at $250 \mathrm{rpm}$ and processed for plate reader assays. For the rhodopsin, excitation was provided at $530 \mathrm{~nm}$ with a $10-\mathrm{nm}$ bandwidth, and the emission was collected from 600-800 nm with a 20-nm bandwidth, a $5 \mathrm{~nm}$-step size, 30 flashes and a gain of 100 (Spark 10M, Tecan). Excitation for CFP was provided at $390 \mathrm{~nm}$ with a 10-nm bandwidth, and the emission collected from 425-560 $\mathrm{nm}$ with a 20-nm bandwidth, a 5-nm step size, 30 flashes, and a gain of 55. For each variant, the rhodopsin emission was integrated from $600-800 \mathrm{~nm}\left(\mathrm{~F}_{\mathrm{GR}}\right)$, and the CFP emission was integrated from $425-560 \mathrm{~nm}\left(\mathrm{~F}_{\mathrm{CFP}}\right)$ using the trapz function in MATLAB. The normalized emission is reported as $\mathrm{F}_{\mathrm{GR}} / \mathrm{F}_{\mathrm{CFP}}$.

Chloride titration assays in live E. coli. Three- $25 \mathrm{~mL}$ cultures of $E$. cloni containing the $w t G R-C F P$ and GR1-CFP plasmids were expressed at $30^{\circ} \mathrm{C}$ as described above. After $4 \mathrm{~h}, 6 \mathrm{~mL}$ of each expression culture was collected by centrifugation 2,500 $\mathrm{g}$ for $5 \mathrm{~min}$ (5810 R, Eppendorf), washed with $3 \mathrm{~mL}$ of $50 \mathrm{mM}$ sodium acetate buffer at $\mathrm{pH} 5$ and resuspended in $400 \mu \mathrm{L}$ of $50 \mathrm{mM}$ sodium acetate buffer at pH 5. In a 96-well plate, $25 \mu \mathrm{L}$ of the cell suspension was diluted with $175 \mu \mathrm{L}$ of $50 \mathrm{mM}$ sodium acetate buffer at $\mathrm{pH} 5$ containing $0,14.3,28.5,57,114.3,228.5$, or $457 \mathrm{mM}$ sodium chloride to a final 
concentration of $0,12.5,25,50,100,200$, and $400 \mathrm{mM}$ sodium chloride. The plate reader measurements were carried out as described above. The GR1-CFP apparent $K_{d}$ for chloride were determined as described above. The average of three technical replicates with standard error of the mean is reported (Figures 4, S19-S20).

This assay was repeated in sodium phosphate buffer to test the effects of sodium acetate. Three-3 mL cultures of E. cloni containing the GR1-CFP plasmid were expressed at 30 ${ }^{\circ} \mathrm{C}$ as described above. After $4 \mathrm{~h}$, the cells were collected by centrifugation $2,500 \mathrm{~g}$ for 5 min (5810 R, Eppendorf), washed with $3 \mathrm{~mL}$ of $50 \mathrm{mM}$ sodium phosphate buffer at $\mathrm{pH} 5$, and resuspended in $200 \mu \mathrm{L}$ of $50 \mathrm{mM}$ sodium phosphate buffer at $\mathrm{pH}$. In a 96-well microtiter plate, $25 \mu \mathrm{L}$ of the cell suspensions were diluted into $175 \mu \mathrm{L}$ of $50 \mathrm{mM}$ sodium phosphate buffer at pH 5 containing $0 \mathrm{mM}, 457 \mathrm{mM}$ sodium chloride, or $457 \mathrm{mM}$ sodium acetate to a final concentration of $0 \mathrm{mM}, 400 \mathrm{mM}$ sodium chloride, or $400 \mathrm{mM}$ sodium acetate. The plate reader measurements were carried out as described above. The average of three biological replicates with standard error of the mean is reported (Figure S21).

To test the reversibility of the chloride response, three- $25 \mathrm{~mL}$ cultures of $E$. cloni containing the GR1-CFP plasmid were expressed at $30{ }^{\circ} \mathrm{C}$ as described above. After 4 $\mathrm{h}, 6 \mathrm{~mL}$ of each expression culture was collected by centrifugation at $2,500 \mathrm{~g}$ for $5 \mathrm{~min}$ (5810 R, Eppendorf), washed with $3 \mathrm{~mL}$ of $50 \mathrm{mM}$ sodium acetate buffer at $\mathrm{pH} 5$, and resuspended in $400 \mu \mathrm{L}$ of buffer. In four- $2 \mathrm{~mL}$ centrifuge tubes (USA Scientific), $75 \mu \mathrm{L}$ of the cell suspensions were diluted into $525 \mu \mathrm{L}$ of $50 \mathrm{mM}$ sodium acetate buffer at $\mathrm{pH} 5$ or buffer containing $457 \mathrm{mM}$ sodium chloride to a final concentration of $0 \mathrm{mM}$ and $400 \mathrm{mM}$ sodium chloride. The cell suspensions were incubated for $10 \mathrm{~min}$ at room temperature with shaking at $300 \mathrm{rpm}$ (ThermoMixer C, Eppendorf). Then, $200 \mu \mathrm{L}$ of the cell suspensions were transferred to a 96-well microtiter plate for plate reader measurements. The remaining cells were collected by centrifugation at $500 \mathrm{~g}$ for $15 \mathrm{~min}$ ( $5424 \mathrm{R}$, Eppendorf), resuspended in $400 \mu \mathrm{L}$ of $50 \mathrm{mM}$ sodium acetate buffer at $\mathrm{pH} 5$ or buffer containing $400 \mathrm{mM}$ sodium chloride or $400 \mathrm{mM}$ sodium gluconate, and incubated for 10 min at room temperature with shaking at $300 \mathrm{rpm}$. The plate reader measurements were repeated with $200 \mu \mathrm{L}$ of the resuspended cells in a 96-well microtiter plate. The average of three biological replicates with standard error of the mean is reported (Figure 4C).

Live $E$. coli imaging and analysis. Three- $3 \mathrm{~mL}$ cultures of $E$. cloni containing the wtGRCFP and GR1-CFP plasmids were expressed at $30^{\circ} \mathrm{C}$ as described above. After $4 \mathrm{~h}$, the cells were collected by centrifugation at 2,500 $\mathrm{g}$ for $5 \mathrm{~min}$ (5810 R, Eppendorf) and resuspended in $100 \mu \mathrm{L}$ of $50 \mathrm{mM}$ sodium acetate buffer at pH 5 . Fifty microliters of each cell suspension was further diluted into $350 \mu \mathrm{L}$ of $50 \mathrm{mM}$ sodium acetate buffer at $\mathrm{pH} 5$, and $3 \mu \mathrm{L}$ of this solution was transferred to a $1.5 \%$ agarose pad and inverted onto a 35 $\mathrm{mm}$ imaging dish with a No. $1.520-\mathrm{mm}$ glass coverslip (MatTek). The agarose pads $(1.5 \%, w / v$, Gold Biotechnology) were prepared in $50 \mathrm{mM}$ sodium acetate buffer at $\mathrm{pH} 5$ containing $0 \mathrm{mM}$ or $400 \mathrm{mM}$ sodium chloride. The agarose was solidified to an even thickness between two microscope slides and cut into $3 \mathrm{~mm}^{2}$ pads. 
Images were acquired using a confocal laser scanning microscope equipped with a single motorized pinhole, a cooled GaAsP photomultiplier, a multi-alkali photomultiplier, a motorized volume phase holographic transmission diffraction grating, a motorized adjustable slit, an external fluorescence light source, and a LED lamp with an integrated external transmitted light photomultiplier detector (FV3000RS, Olympus). A UPLSAPO 100X silicone immersion objective with a numerical aperture of 1.35 and working distance of $0.2 \mathrm{~mm}$ was used for imaging. Z-stacks were acquired for each sample. First, the rhodopsin was excited at $561 \mathrm{~nm}(20 \mathrm{~mW})$, and the emission was collected from 630$730 \mathrm{~nm}$. Then, the CFP was excited at $405 \mathrm{~nm}(50 \mathrm{~mW})$, and the emission collected from 405-505 nm. Images were analyzed using the Fiji Is Just Image J (Fiji) v2.0 software. ${ }^{[107]}$ Default threshold settings were applied to the CFP maximum intensity Z-projection to create masks. From the masks, regions of interest (ROls) with pixels greater than 3 and circularity between 0 and 1 were selected using the Analyze Particles function in Fiji. Overlapping cells that could not be identified as single cells were grouped as one ROI. For each Z-stack, the ROls were transferred to the maximum intensity Z-projection of both the rhodopsin and CFP channels, and the fluorescence median intensity was measured. For each biological replicate $(n=3)$, at least four different fields of cells were sampled. The median fluorescence intensity of the rhodopsin $\left(F_{G R}\right)$ was normalized to the median fluorescence intensity of CFP ( $\left.\mathrm{F}_{\mathrm{CFP}}\right)$ (Figures 5, S22).

Proton and chloride-pumping assays in live E. coli. Proton and chloride pumping activities were measured using modified literature procedures. ${ }^{[94]}$ Three- $25 \mathrm{~mL}$ cultures of $E$. cloni containing the wtGR-CFP and GR1-CFP plasmids were expressed at $30^{\circ} \mathrm{C}$ as described above. After $4 \mathrm{~h}$, the cells were collected by centrifugation at 3,000 (Allegra $\mathrm{X}-14 \mathrm{R}$, Beckman Coulter) for $5 \mathrm{~min}$ at $4{ }^{\circ} \mathrm{C}$, washed 3 times with $10 \mathrm{~mL}$ of $400 \mathrm{mM}$ sodium chloride, and resuspended in $4 \mathrm{~mL}$ of $400 \mathrm{mM}$ sodium chloride to a final $\mathrm{OD}_{600} \sim 0.8$. The cells were incubated in the dark for $1 \mathrm{~h}$ at $4{ }^{\circ} \mathrm{C}$ and then illuminated with a $90-\mathrm{W}$ BR40 LED light bulb (EcoSmart, Home Depot) for 2 min. Light induced $\mathrm{pH}$ changes were measured using a pH electrode (Mettler Toledo) every $10 \mathrm{~s}$ for $300 \mathrm{~s}$. The summation of the change in $\mathrm{pH}(\Delta \mathrm{pH})$ was calculated for each time point. Pumping assays were also carried out with cells treated with carbonyl cyanide 3-chlorophenylhydrazone (CCCP, Sigma-Aldrich). A stock solution of $10 \mathrm{mM}$ CCCP was prepared in DMSO and $12 \mu \mathrm{L}$ of the stock solution was added to the $4 \mathrm{~mL}$ cell resuspension to a final concentration of 30 $\mu \mathrm{M}$ CCCP. The average $\Delta \mathrm{pH}$ for three biological replicates with standard error of the mean is reported (Figure S23).

Chloride titrations in live E. coli with CCCP. To validate that the GR1-CFP turn-on response to chloride is independent of the membrane potential, chloride titrations were carried out with cells treated with $30 \mu \mathrm{M}$ CCCP. Three- $3 \mathrm{~mL}$ cultures of $E$. cloni containing the wtGR-CFP and GR1-CFP plasmids were expressed at $30^{\circ} \mathrm{C}$ as described above. After $4 \mathrm{~h}$, each expression culture was collected by centrifugation $2,500 \mathrm{~g}$ for $5 \mathrm{~min}$ (5810 $\mathrm{R}$, Eppendorf) and resuspended in $400 \mu \mathrm{L}$ of $50 \mathrm{mM}$ sodium acetate buffer at $\mathrm{pH} 5$. In a 96-well plate, $10 \mu \mathrm{L}$ of the cell suspension was diluted into $175 \mu \mathrm{L}$ of $50 \mathrm{mM}$ sodium acetate buffer at $\mathrm{pH} 5$ containing $0,14.3,28.5,57,114.3,228.5$, or $457 \mathrm{mM}$ sodium chloride to a final concentration of $0,12.5,25,50,100,200$, and $400 \mathrm{mM}$ sodium chloride. Each well was further diluted with $15 \mu \mathrm{L}$ of $3.2 \%$ DMSO $(\mathrm{v} / \mathrm{v})$ in buffer as the control or 
$400 \mu \mathrm{M}$ CCCP in buffer for a final concentration of $0 \mu \mathrm{M}$ and $30 \mu \mathrm{M} \mathrm{CCCP.} \mathrm{The} \mathrm{96-well}$ microtiter plate was incubated at $30^{\circ} \mathrm{C}$ for 30 min with shaking for 1 min every 5 min in the plate reader. The plate reader measurements were carried using the settings described above. The average of three biological replicates with standard error of the mean is reported (Figure S24).

Membrane potential measurements with $\mathrm{DiOC}_{2}(3)$. To confirm that CCCP treatment at $\mathrm{pH} 5$ uncouples the membrane potential, experiments were carried out with the ratiometric dye 3-3'-diethlyoxacarbocyanine iodide ( $\mathrm{DiOC}_{2}$ (3), Alfa Aesar). ${ }^{[98]}$ Three-5 mL cultures of $E$. cloni containing the GR1-CFP plasmid were incubated overnight at $37^{\circ} \mathrm{C}$ with shaking at $250 \mathrm{rpm}$. The following day, $1 \mathrm{~mL}$ of the overnight cultures were harvested by centrifugation at 2,500 $\mathrm{g}$ for $5 \mathrm{~min}$ (5810 R, Eppendorf) and resuspended with $1 \mathrm{~mL}$ of $50 \mathrm{mM}$ sodium acetate buffer at $\mathrm{pH} 5$. A portion of the cell resuspension $(119 \mu \mathrm{L})$ was transferred to a 5-mL Falcon Round-Bottom Polystyrene Tube (Corning) and further diluted into $875 \mu \mathrm{L}$ of sodium acetate buffer at pH 5 containing $0 \mathrm{mM}, 457 \mathrm{mM}$ sodium chloride, or $457 \mathrm{mM}$ sodium gluconate to a final concentration of $0 \mathrm{mM}, 400 \mathrm{mM}$ sodium chloride, or $400 \mathrm{mM}$ sodium gluconate. The samples were then treated with $1 \mu \mathrm{L}$ of DMSO or $1 \mu \mathrm{L}$ of a $30 \mathrm{mM}$ CCCP stock solution in DMSO and $4 \mu \mathrm{L}$ of an $11 \mathrm{mM} \mathrm{DiOC}_{2}(3)$ stock solution in DMSO for a final concentration of $0 \mu \mathrm{M}$ or $30 \mu \mathrm{M}$ CCCP and $22 \mu \mathrm{M} \mathrm{DiOC}_{2}(3)$. The samples were incubated in the dark at room temperature for 30 min before flow cytometry measurements (BD LSRFortessa). Cells were excited with the $488 \mathrm{~nm}$ laser (50 $\mathrm{mW}$ power). The green and red emissions were collected using the FITC emission at $530 \mathrm{~nm}$ with a $30-\mathrm{nm}$ bandpass and the PerCP-Cy5-5 emission at $710 \mathrm{~nm}$ with a $50-\mathrm{nm}$ bandpass, respectively. For each sample 50,000 events were recorded. Unstained and untreated $E$. cloni in $50 \mathrm{mM}$ sodium acetate buffer at $\mathrm{pH} 5$ were used as negative controls to gate cell populations using the software FlowJo v10.8. For each treatment, the average median emission intensity of three biological replicates with standard error of the mean is reported (Figure S25).

\section{Supporting Information}

Nucleotide sequences and primers, polymerase chain reaction conditions, Coomassie stained SDS-PAGE gels, absorbance and fluorescence spectra, saturation curves, quantum yields, fluorescence microscopy analysis, proton and chloride pumping assays, flow cytometry scatter and fluorescence plots, and membrane potential assays are provided in the Supporting Information.

\section{AUTHOR INFORMATION}

\section{Corresponding Author}

`E-mail: sheel.dodani@utdallas.edu

\section{ORCID}

Jasmine N. Tutol: 0000-0001-8493-4203 
Jessica Lee: 0000-0003-1521-3677

Hsichuan Chi: 0000-0002-6491-8553

Sameera S. Abeyrathna: 0000-0002-1346-6796

Qin Zhou: 0000-0002-7269-1731

Faruck Morcos: 0000-0001-6208-1561

Gabriele Meloni: 0000-0003-4976-1401

Sheel C. Dodani: 0000-0003-0271-6080

\section{Author Contributions}

J.N.T, J.L., C.H., F.F., and S.C.D designed and performed research and analyzed data. S.S.A and G.M. contributed technical expertise for protein purification. Q.Z. and F.M. generated the multiple sequence alignment of the rhodopsin family. J.N.T. and S.C.D. wrote the manuscript.

\section{Funding}

F.M. acknowledges support from the National Science Foundation (MCB-1943442) and the National Institute of General Medical Sciences of the National Institutes of Health (R35GM133631). G.M. acknowledges support from the Welch Foundation (AT1935-20170325) and the National Institute of General Medical Sciences of the National Institutes of Health (R35GM128704). S.C.D. acknowledges support from startup funds provided by The University of Texas at Dallas startup, the Welch Foundation (AT-191820170325), and the National Institute of General Medical Sciences of the National Institutes of Health (R35GM128923). This work is the sole responsibility of the authors and does represent the views of the funding agencies.

\section{Notes}

The authors have no competing financial interests.

\section{Acknowledgements}

We thank members of the Dodani and Meloni labs, Dr. Alexander R. Lippert, Dr. John W. Sibert, and Dr. Ronald A. Smaldone for helpful discussions. We also acknowledge Dr. Jacob Henderson (Flow Cytometry Core at UT Dallas) and Dr. Ved Prakash (Olympus Discovery Center at UT Dallas) for expert technical assistance with method development and data analysis. 


\section{REFERENCES}

(1) Raven, J. A.; Raines, C. Chloride: essential micronutrient and multifunctional beneficial ion. J. Exp. Bot. 2017, 68, 359-367.

(2) Lindh, U. Biological Functions of the Elements. In Essentials of Medical Geology; Springer Netherlands: Dordrecht, 2013; pp 129-177.

(3) Jentsch, T. J.; Pusch, M. CLC chloride channels and transporters: structure, function, physiology, and disease. Physiol Rev 2018, 98, 1493-1590.

(4) Zajac, M.; Chakraborty, K.; Saha, S.; Mahadevan, V.; Infield, D. T.; Accardi, A.; Qiu, Z.; Krishnan, Y. What biologists want from their chloride reporters - a conversation between chemists and biologists. J. Cell Sci. 2020, 133, jcs240390.

(5) Heubl, M.; Zhang, J.; Pressey, J. C.; Al Awabdh, S.; Renner, M.; Gomez-Castro, F.; Moutkine, I.; Eugène, E.; Russeau, M.; Kahle, K. T.; et al. GABAA receptor dependent synaptic inhibition rapidly tunes $\mathrm{KCC} 2$ activity via the $\mathrm{Cl}^{-}$-sensitive WNK1 kinase. Nat. Commun. 2017, 8, 1776.

(6) Wasiluk, T.; Roueinfar, M.; Hiryak, K.; Torsiello, M.; Miner, A.; Lee, J.; Venditto, M.; Terzaghi, W.; Lucent, D.; VanWert, A. L. Simultaneous expression of ClopHensor and SLC26A3 reveals the nature of endogenous oxalate transport in $\mathrm{CHO}$ cells. Biol. Open 2019, 8, 1-8.

(7) Roebber, J. K.; Roper, S. D.; Chaudhari, X. N. The role of the anion in salt (NaCl) detection by mouse taste buds. J. Neurosci. 2019, 39, 6224-6232.

(8) Yang, J.; Chen, J.; Del Carmen Vitery, M.; Osei-Owusu, J.; Chu, J.; Yu, H.; Sun, S.; Quu, Z. PAC, an evolutionarily conserved membrane protein, is a proton-activated chloride channel. Science 2019, 364, 395-399.

(9) Ullrich, F.; Blin, S.; Lazarow, K.; Daubitz, T.; Peter Von Kries, J.; Jentsch, T. J. Identification of TMEM206 proteins as pore of PAORAC/ASOR acid-sensitive chloride channels. eLife 2019, 8, 1-25.

(10) Kubik, S. Anion recognition in water. Chem. Soc. Rev. 2010, 39, 3648-3663.

(11) Ashton, T.; Jolliffe, K. A.; Pfeffer, F. M. Luminescent probes for the bioimaging of small anionic species in vitro and in vivo. Chem Soc Rev 2014, 44, 4547-4595.

(12) Langton, M. J.; Serpell, C. J.; Beer, P. D. Anion recognition in water: recent advances from a supramolecular and macromolecular perspective. Angew. Chem. Int. Ed. 2016, 55, 1974-1987.

(13) Steed, J. W.; Atwood, J. L. Supramolecular Chemistry, 2nd ed.; John Wiley \& Sons, Ltd, 2009.

(14) Okur, H. I.; Hladílková, J.; Rembert, K. B.; Cho, Y.; Heyda, J.; Dzubiella, J.; Cremer, P. S.; Jungwirth, P. Beyond the Hofmeister series: lon-specific effects on proteins and their biological functions. J. Phys. Chem. B 2017, 121, 1997-2014.

(15) Cremer, P. S.; Flood, A. H.; Gibb, B. C.; Mobley, D. L. Collaborative routes to clarifying the murky waters of aqueous supramolecular chemistry. Nat. Chem. 2018, 10, 8-16.

(16) Gassensmith, J. J.; Matthys, S.; Lee, J.-J.; Wojcik, A.; Kamat, P. V; Smith, B. D. Squaraine rotaxane as a reversible optical chloride sensor. Chem. Eur. J 2010, 16, 2916-2921.

(17) Amatori, S.; Ambrosi, G.; Borgogelli, E.; Fanelli, M.; Formica, M.; Fusi, V.; Giorgi, L.; Macedi, E.; Micheloni, M.; Paoli, P.; et al. Modulating the sensor response to halide using NBD-based azamacrocycles. Inorg. Chem 2014, 53, 4560-4569.

(18) Kim, J. P.; Xie, Z.; Creer, M.; Liu, Z.; Yang, J. Citrate-based fluorescent materials for lowcost chloride sensing in the diagnosis of cystic fibrosis. Chem. Sci. 2017, 8, 550-558.

(19) Watt, M. M.; Engle, J. M.; Fairley, K. C.; Robitshek, T. E.; Haley, M. M.; Johnson, D. W. "Off-on" aggregation-based fluorescent sensor for the detection of chloride in water. Org. Biomol. Chem. 2015, 13, 4266-4270.

(20) Vallejos, S.; Hernando, E.; Trigo, M.; García, F.; García-Valverde, M.; Iturbe, D.; Cabero, 
M. J.; Quesada, R.; García, J. M. Polymeric chemosensor for the detection and quantification of chloride in human sweat. Application to the diagnosis of cystic fibrosis. $J$. Mater. Chem. B 2018, 6, 3735-3741.

(21) Verkman, A. S. Development and biological applications of chloride-sensitive fluorescent indicators. Am. J. Physiol. 1990, 259, C375-C388.

(22) Geddes, C. D. Optical halide sensing using fluorescence quenching: theory, simulations and applications - a review. Meas. Sci. Technol. 2001, 12, R53-R88.

(23) Sonawane, N. D.; Thiagarajah, J. R.; Verkman, A. S. Chloride concentration in endosomes measured using a ratioable fluorescent $\mathrm{Cl}^{-}$indicator. J. Biol. Chem. 2002, 277, 5506-5513.

(24) Graefe, A.; Stanca, S. E.; Nietzsche, S.; Kubicova, L.; Beckert, R.; Biskup, C.; Mohr, G. J. Development and critical evaluation of fluorescent chloride nanosensors. Anal. Chem 2008, 80, 6526-6531.

(25) Saha, S.; Prakash, V.; Halder, S.; Chakraborty, K.; Krishnan, Y. A pH-independent DNA nanodevice for quantifying chloride transport in organelles of living cells. Nat. Nanotechnol. 2015, 10, 645-652.

(26) Prakash, V.; Saha, S.; Chakraborty, K.; Krishnan, Y. Rational design of a quantitative, pHinsensitive, nucleic acid based fluorescent chloride reporter. Chem. Sci. 2016, 7, 19461953.

(27) Chakraborty, K.; Leung, K.; Krishnan, Y. High lumenal chloride in the lysosome is critical for lysosome function. eLife 2017, 6, 1-21.

(28) Park, S. H.; Hyun, J. Y.; Shin, I. A lysosomal chloride ion-selective fluorescent probe for biological applications. Chem. Sci. 2019, 10, 56-66.

(29) Romero, P. A.; Arnold, F. H. Exploring protein fitness landscapes by directed evolution. Nat. Rev. Mol. Cell Biol. 2009, 10, 866-876.

(30) Chudakov, D. M.; Matz, M. V.; Lukyanov, S.; Lukyanov, K. A. Fluorescent proteins and their applications in imaging living cells and tissues. Physiol. Rev. 2010, 90, 1103-1163.

(31) Arosio, D.; Ratto, G. M. Twenty years of fluorescence imaging of intracellular chloride. Front. Cell. Neurosci. 2014, 8, 1-12.

(32) Wachter, R. M.; Elsliger, M.-A.; Kallio, K.; Hanson, G. T.; Remington, J. Structural basis of spectral shifts in the yellow-emission variants of green fluorescent protein. Structure 1998, 6, 1267-1277.

(33) Wachter, R. M.; James Remington, S. Sensitivity of the yellow variant of green fluorescent protein to halides and nitrate. Curr. Biol. 1999, 9, R628-R629.

(34) Wachter, R. M.; Yarbrough, D.; Kallio, K.; Remington, S. J. Crystallographic and energetic analysis of binding of selected anions to the yellow variants of green fluorescent protein. $J$. Mol. Biol. 2000, 301, 157-171.

(35) Jayaraman, S.; Haggie, P.; Wachter, R. M.; Remington, S. J.; Verkman, A. S. Mechanism and cellular applications of a green fluorescent protein-based halide sensor. J. Biol. Chem. 2000, 275, 6047-6050.

(36) Arosio, D.; Garau, G.; Ricci, F.; Marchetti, L.; Bizzarri, R.; Nifosì, R.; Beltram, F. Spectroscopic and structural study of proton and halide ion cooperative binding to GFP. Biophys. J. 2007, 93, 232-244.

(37) Galietta, L. J. V; Haggie, P. M.; Verkman, A. S. Green fluorescent protein-based halide indicators with improved chloride and iodide affinities. FEBS Lett. 2001, 499, 220-224.

(38) Nagai, T.; Ibata, K.; Park, E. S.; Kubota, M.; Mikoshiba, K.; Miyawaki, A. A variant of yellow fluorescent protein with fast and efficient maturation for cell-biological applications. Nat. Biotechnol. 2002, 20, 87-90.

(39) Markova, O.; Mukhtarov, M.; Real, E.; Jacob, Y.; Bregestovski, P. Genetically encoded chloride indicator with improved sensitivity. J. Neurosci. Methods 2008, 170, 67-76.

(40) Watts, S. D.; Suchland, K. L.; Amara, S. G.; Ingram, S. L. A sensitive membrane-targeted biosensor for monitoring changes in intracellular chloride in neuronal processes. PLoS One 
2012, 7, 1-9.

(41) Zhong, S.; Navaratnam, D.; Santos-Sacchi, J. A genetically-encoded YFP sensor with enhanced chloride sensitivity, photostability and reduced $\mathrm{pH}$ interference demonstrates augmented transmembrane chloride movement by gerbil prestin (SLC26a5). PLoS One 2014, 9, 1-9.

(42) Kuner, T.; Augustine, G. J. A genetically encoded ratiometric indicator for chloride: Capturing chloride transients in cultured hippocampal neurons. Neuron 2000, 27, 447-459.

(43) Waseem, T.; Mukhtarov, M.; Buldakova, S.; Medina, I.; Bregestovski, P. Genetically encoded $\mathrm{Cl}$-Sensor as a tool for monitoring of $\mathrm{Cl}$-dependent processes in small neuronal compartments. J. Neurosci. Methods 2010, 193, 14-23.

(44) Arosio, D.; Ricci, F.; Marchetti, L.; Gualdani, R.; Albertazzi, L.; Beltram, F. Simultaneous intracellular chloride and $\mathrm{pH}$ measurements using a GFP-based sensor. Nat. Methods 2010, 7, 516-518.

(45) Mukhtarov, M.; Liguori, L.; Waseem, T.; Rocca, F.; Buldakova, S.; Arosio, D.; Bregestovski, P. Calibration and functional analysis of three genetically encoded $\mathrm{Cl}^{-} / \mathrm{pH}$ sensors. Front. Mol. Neurosci. 2013, 6, 1-12.

(46) Paredes, J. M.; Idilli, A. I.; Mariotti, L.; Losi, G.; Arslanbaeva, L. R.; Sato, S. S.; Artoni, P.; Szczurkowska, J.; Cancedda, L.; Ratto, G. M.; et al. Synchronous bioimaging of intracellular $\mathrm{pH}$ and chloride based on LSS fluorescent protein. ACS Chem. Biol. 2016, 11, 1652-1660.

(47) Sato, S. S.; Artoni, P.; Landi, S.; Cozzolino, O.; Parra, R.; Pracucci, E.; Trovato, F.; Szczurkowska, J.; Luin, S.; Arosio, D.; et al. Simultaneous two-photon imaging of intracellular chloride concentration and $\mathrm{pH}$ in mouse pyramidal neurons in vivo.

(48) Tutol, J. N.; Peng, W.; Dodani, S. C. Discovery and characterization of a naturally occurring, turn-on yellow fluorescent protein sensor for chloride. Biochemistry 2019, 58, 31-35.

(49) Tutol, J. N.; Kam, H. C.; Dodani, S. C. Identification of mNeonGreen as a pH-dependent, turn-on fluorescent protein sensor for chloride. ChemBioChem 2019, 20, 1759-1765.

(50) Pletneva, N. V; Pletnev, V. Z.; Souslova, E.; Chudakov, D. M.; Lukyanov, S.; Martynov, V. I.; Arhipova, S.; Artemyev, I.; Wlodawer, A.; Dauter, Z.; et al. Yellow fluorescent protein phiYFPv (Phialidium): structure and structure-based mutagenesis. Acta Crystallogr. Sect. D 2013, 69, 1005-1012.

(51) Clavel, D.; Gotthard, G.; Von Stetten, D.; De Sanctis, D.; Pasquier, H.; Lambert, G. G.; Shaner, N. C.; Royant, A. Structural analysis of the bright monomeric yellow-green fluorescent protein $\mathrm{mNeonGreen} \mathrm{obtained} \mathrm{by} \mathrm{directed} \mathrm{evolution.} \mathrm{Acta} \mathrm{Cryst.} \mathrm{2016,} \mathrm{D72,}$ 1298-1307.

(52) Klare, J. P.; Chizhov, I.; Engelhard, M. Microbial rhodopsins: Scaffolds for ion pumps, channels, and sensors. Results Probl. Cell. Differ. 2007, 45, 73-122.

(53) Yizhar, O.; Fenno, L.; Zhang, F.; Hegemann, P.; Diesseroth, K. Microbial opsins: A family of single-component tools for optical control of neural activity. Cold Spring Harb. Protoc. 2011, 3, 273-282.

(54) Ernst, O. P.; Lodowski, D. T.; Elstner, M.; Hegemann, P.; Brown, L. S.; Kandori, H. Microbial and animal rhodopsins: Structures, functions, and molecular mechanisms. Chem. Rev. 2014, 114, 126-163.

(55) Kurihara, M.; Sudo, Y. Microbial rhodopsins: wide distribution, rich diversity and great potential. Biophys. Physicobiology 2015, 12, 121-129.

(56) Govorunova, E. G.; Sineshchekov, O. A.; Li, H.; Spudich, J. L. Microbial rhodopsins: Diversity, mechanisms, and optogenetic applications. Annu. Rev. Biochem. 2017, 86, 845872.

(57) Tsutsui, K.; Shichida, Y. Multiple functions of Schiff base counterion in rhodopsins. Photochem. Photobiol. Sci. 2010, 9, 1426-1434. 
(58) Kolbe, M.; Besir, H.; Essen, L. O.; Oesterhelt, D.; Boyer, P. D.; Oesterhelt, D.; Rosen, B. P.; Ikeda, M.; Oesterhelt, D.; Oesterhelt, D.; et al. Structure of the light-driven chloride pump halorhodopsin at $1.8 \AA$ resolution. Science 2000, 288, 1390-1396.

(59) Kouyama, T.; Kanada, S.; Takeguchi, Y.; Narusawa, A.; Murakami, M.; Ihara, K. Crystal structure of the light-driven chloride pump halorhodopsin from Natronomonas pharaonis. J. Mol. Biol. 2010, 396, 564-579.

(60) Inoue, K.; Kato, Y.; Kandori, H. Light-driven ion-translocating rhodopsins in marine bacteria. Trends Microbiol. 2015, 23, 91-98.

(61) Schreiner, M.; Schlesinger, R.; Heberle, J.; Niemann, H. H. Structure of halorhodopsin from Halobacterium salinarum in a new crystal form that imposes little restraint on the E-F loop. J. Struct. Biol. 2015, 190, 373-378.

(62) Kim, K.; Kwon, S.-K.; Jun, S.-H.; Cha, J. S.; Kim, H.; Lee, W.; Kim, J. F.; Cho, H.-S. Crystal structure and functional characterization of a light-driven chloride pump having an NTQ motif. Nat. Commun. 2016, 7, 1-10.

(63) Besaw, J. E.; Ou, W.-L.; Morizumi, T.; Eger, B. T.; Sanchez Vasquez, J. D.; Chu, J. H. Y.; Harris, A.; Brown, L. S.; Dwayne Miller, R. J.; Ernst, O. P. Structural insight into functional conversion of a Cl-pump The crystal structures of a chloride-pumping microbial rhodopsin and its proton-pumping mutant illuminate proton transfer determinants. J. Biol. Chem. 2020, doi: 10.1074/jbc.RA120.014118.

(64) Facciotti, M. T.; Rouhani, S.; Burkard, F. T.; Betancourt, F. M.; Downing, K. H.; Rose, R. B.; McDermott, G.; Glaeser, R. M. Structure of an early Intermediate in the M-state phase of the bacteriorhodopsin photocycle. Biophys. J. 2001, 81, 3442-3455.

(65) Sasaki, J.; Brown, L. S.; Chon, Y.-S.; Kandori, H.; Maeda, A.; Needleman, R.; Lanyi, J. K. Conversion of bacteriorhodopsin into a chloride ion pump. Science 1995, 269, 73-75.

(66) Brown, L. S.; Needleman, R.; Lanyi, J. K. Interaction of proton and chloride transfer pathways in recombinant bacteriorhodopsin with chloride transport activity: Implications for the chloride translocation mechanism. Biochemistry 1996, 35, 16048-16054.

(67) Tittor, J.; Haupts, U.; Haupts, C.; Oesterhelt, D.; Becker, A.; Bamberg, E. Chloride and proton transport in bacteriorhodopsin mutant D85T: different modes of ion translocation in a retinal protein. J. Mol. Biol. 1997, 271, 405-416.

(68) Ganea, C.; Tittor, J.; Bamberg, E.; Oesterhelt, D. Chloride- and pH-dependent proton transport by BR mutant D85N. Biochim. Biophys. Acta 1998, 1368, 84-96.

(69) Facciotti, M. T.; Cheung, V. S.; Nguyen, D.; Rouhani, S.; Glaeser, R. M. Crystal structure of the bromide-bound D85S mutant of bacteriorhodopsin: principles of ion pumping. Biophys. J. 2003, 85, 451-458.

(70) Bogomolni, R. A.; Stubbs, L.; Lanyi, J. K. Illumination-dependent changes in the intrinsic fluorescence of bacteriorhodopsin. Biochemistry 1978, 17, 1037-1041.

(71) Kralj, J. M.; Hochbaum, D. R.; Douglass, A. D.; Cohen, A. E. Electrical spiking in Escherichia coli probed with a fluorescent voltage-indicating protein. Science 2011, 333, 345-348.

(72) Maclaurin, D.; Venkatachalam, V.; Lee, H.; Cohen, A. E. Mechanism of voltage-sensitive fluorescence in a microbial rhodopsin. Proc. Natl. Acad. Sci. USA. 2013, 110, 5939-5944.

(73) Yu, J. K.; Liang, R.; Liu, F.; Martínez, T. J. First-principles characterization of the elusive I fluorescent state and the structural evolution of retinal protonated Schiff base in bacteriorhodopsin. J. Am. Chem. Soc. 2019, 141, 18193-18203.

(74) Kralj, J. M.; Douglass, A. D.; Hochbaum, D. R.; Maclaurin, D.; Cohen, A. E. Optical recording of action potentials in mammalian neurons using a microbial rhodopsin. Nat. Methods 2012, 9, 90-95.

(75) Bando, Y.; Grimm, C.; Cornejo, V. H.; Yuste, R. Genetic voltage indicators. BMC Biol. 2019, 17, 1-12.

(76) Kojima, K.; Shibukawa, A.; Sudo, Y. The unlimited potential of microbial rhodopsins as 
optical tools. Biochemistry 2020, 59, 218-229.

Nakamura, Y.; Kaneko, T.; Sato, S.; Mimuro, M.; Miyashita, H.; Tsuchiya, T.; Sasamoto, S.; Watanabe, A.; Kawashima, K.; Kishida, Y.; et al. Complete genome structure of Gloeobacter violaceus PCC 7421, a cyanobacterium that lacks thylakoids. DNA Res. 2003, 10, 137-145.

(78) Miranda, M. R. M.; Choi, A. R.; Shi, L.; Bezerra, A. G.; Jung, K.-H.; Brown, L. S. The photocycle and proton translocation pathway in a cyanobacterial ion-pumping rhodopsin. Biophys. J. 2009, 96, 1471-1481.

(79) Ganapathy, S.; Venselaar, H.; Chen, Q.; De Groot, H. J. M.; Hellingwerf, K. J.; De Grip, W. J. Retinal-based proton pumping in the near infrared. J. Am. Chem. Soc. 2017, 139, 23382344.

(80) Morizumi, T.; Ou, W.-L.; Van Eps, N.; Inoue, K.; Kandori, H.; Brown, L. S.; Ernst, O. P. Xray crystallographic structure and oligomerization of Gloeobacter rhodopsin. Sci. Rep. 2019, 9, 1-14.

(81) Jana, S.; Jung, K. H.; Sheves, M. The chirality origin of retinal-carotenoid complex in gloeobacter rhodopsin: a temperature-dependent excitonic coupling. Sci. Rep. 2020, 10, $1-13$.

(82) Imasheva, E. S.; Balashov, S. P.; Choi, A. R.; Jung, K.-H.; Lanyi, J. K. Reconstitution of Gloeobacter violaceus rhodopsin with a light-harvesting carotenoid antenna. Biochemistry 2009, 48, 10948-10955.

(83) Hashimoto, K.; Choi, A. R.; Furutani, Y.; Jung, K.-H.; Kandori, H. Low-temperature FTIR study of Gloeobacter rhodopsin: Presence of strongly hydrogen-bonded water and longrange structural protein perturbation upon retinal photoisomerization. Biochemistry 2010, 49, 3343-3350.

(84) Vogt, A.; Wietek, J.; Hegemann, P. Gloeobacter rhodopsin, limitation of proton pumping at high electrochemical load. Biophys. J. 2013, 105, 2055-2063.

(85) Tsukamoto, T.; Kikukawa, T.; Kurata, T.; Jung, K.-H.; Kamo, N.; Demura, M. Salt bridge in the conserved His-Asp cluster in Gloeobacter rhodopsin contributes to trimer formation. FEBS Lett. 2013, 587, 322-327.

(86) Tsukamoto, T.; Inoue, K.; Kandori, H.; Sudo, Y. Thermal and spectroscopic characterization of a proton pumping rhodopsin from an extreme thermophile. J. Biol. Chem. 2013, 288, 21581-21592.

(87) Choi, A. R.; Shi, L.; Brown, L. S.; Jung, K.-H. Cyanobacterial light-driven proton pump, Gloeobacter rhodopsin: Complementarity between rhodopsin-based energy production and photosynthesis. PLoS One 2014, 9, e110643.

(88) Engqvist, M. K. M.; Mclsaac, R. S.; Dollinger, P.; Flytzanis, N. C.; Abrams, M.; Schor, S.; Arnold, F. H. Directed evolution of Gloeobacter violaceus rhodopsin spectral properties. J. Mol. Biol. 2015, 427, 205-220.

(89) Jana, S.; Eliash, T.; Jung, K.-H.; Sheves, M. Retinal binding to apo-Gloeobacter rhodopsin: The role of $\mathrm{pH}$ and retinal-carotenoid interaction. J. Phys. Chem. B 2017, 121, 1075910769.

(90) Kaushik, J. K.; Bhat, R. A mechanistic analysis of the increase in the thermal stability of proteins in aqueous carboxylic acid salt solutions. Protein Sci. 1999, 8, 222-223.

(91) Facciotti, M. T.; Cheung, V. S.; Lunde, C. S.; Rouhani, S.; Baliga, N. S.; Glaeser, R. M. Specificity of anion binding in the substrate pocket of bacteriorhodopsin. Biochemistry 2004, 43, 4934-4943.

(92) Mangani, S.; Ferraroni, M. Natural Anion Receptors: Anion Recognition by Proteins. In Supramolecular Chemistry of Anions; Bianchi, A., Bowman-James, K., García-España, E., Eds.; John Wiley \& Sons, Inc.: New York City, 1997; pp 63-78.

(93) Wilks, J. C.; Slonczewski, J. L. pH of the cytoplasm and periplasm of Escherichia coli: Rapid measurement by green fluorescent protein fluorimetry. J. Bacteriol. 2007, 189, 
5601-5607.

(94) Hasemi, T.; Kikukawa, T.; Kamo, N.; Demura, M. Characterization of a cyanobacterial chloride-pumping rhodopsin and its conversion into a proton pump. J. Biol. Chem. 2016, 291, 355-362.

(95) Saeedi, P.; Moosaabadi, J. M.; Sebtahmadi, S. S.; Mehrabadi, J. F.; Behmanesh, M.; Nejad, H. R.; Nazaktabar, A. Generation and analysis of bacteriorhodopsin mutants with the potential for biotechnological applications. Bioengineered 2012, 3, 275-279.

(96) Yoshizawa, S.; Kumagai, Y.; Kim, H.; Ogura, Y.; Hayashi, T.; Iwasaki, W.; DeLong, E. F.; Kogure, K. Functional characterization of flavobacteria rhodopsins reveals a unique class of light-driven chloride pump in bacteria. Proc. Natl. Acad. Sci. USA. 2014, 111, 67326737.

(97) Inoue, K.; Ito, S.; Kato, Y.; Nomura, Y.; Shibata, M.; Uchihashi, T.; Tsunoda, S. P.; Kandori, H. A natural light-driven inward proton pump. Nat. Commun. 2016, 7, 1-10.

(98) Novo, D.; Perlmutter, N. G.; Hunt, R. H.; Shapiro, H. M. Accurate flow cytometric membrane potential measurement in bacteria using diethyloxacarbocyanine and a ratiometric technique. Cytometry 1999, 35, 55-63.

(99) Kille, S.; Acevedo-Rocha, C. G.; Parra, L. P.; Zhang, Z.-G.; Opperman, D. J.; Reetz, M. T.; Acevedo, J. P. Reducing codon redundancy and screening effort of combinatorial protein libraries created by saturation mutagenesis. ACS Synth. Biol. 2013, 2, 83-92.

(100) Eddy, S. R. Accelerated profile HMM searches. PLoS Comput. Biol. 2011, 7, 1-16.

(101) Potter, S. C.; Luciani, A.; Eddy, S. R.; Park, Y.; Lopez, R.; Finn, R. D. HMMER web server: 2018 update. Nucleic Acids Res. 2018, 46, W200-W204.

(102) Mclsaac, R. S.; Engqvist, M. K. M.; Wannier, T.; Rosenthal, A. Z.; Herwig, L.; Flytzanis, N. C.; Imasheva, E. S.; Lanyi, J. K.; Balashov, S. P.; Gradinaru, V.; et al. Directed evolution of a far-red fluorescent rhodopsin. Proc. Natl. Acad. Sci. USA. 2012, 111, 13034-13039.

(103) Robeson, C. D.; Blum, W. P.; Dieterle, J. M.; Cawley, J. D.; Baxter, J. G. Chemistry of vitamin A. XXV. Geometrical isomers of vitamin A aldehyde and an isomer of its alphaionone analog. J. Am. Chem. Soc. 1955, 77, 4120-4125.

(104) Karstens, T.; Kobs, K. Rhodamine B and rhodamine 101 as reference substances for fluorescence quantum yield measurements. J. Phys. Chem. 1980, 84, 1871-1872.

(105) Hale, G. M.; Querry, M. R. Optical constants of water in the 200-nm to 200-microm wavelength region. Appl. Opt. 1973, 12, 555-563.

(106) Kozma, I. Z.; Krok, P.; Riedle, E. Direct measurement of the group-velocity mismatch and derivation of the refractive-index dispersion for a variety of solvents in the ultraviolet. $J$. Opt. Soc. Am. B 2005, 22, 1479-1485.

(107) Schindelin, J.; Arganda-Carreras, I.; Frise, E.; Kaynig, V.; Longair, M.; Pietzsch, T.; Preibisch, S.; Rueden, C.; Saalfeld, S.; Schmid, B.; et al. Fiji: an open-source platform for biological-image analysis. Nat. Methods 2012, 9, 676-682. 